\title{
DE LA FABRICACIÓN DE COMPONENTES ELECTRÓNICOS PASIVOS
}

\section{THE MANUFACTURING OF PASSIVE ELECTRONIC COMPONENTS}

\begin{abstract}
Arturo Pérez París: Universidad de Alcalá. Madrid (España).
\end{abstract} arturo.perez@mixmail.com

\section{CURRÍCULUM VITAE}

Escuela Politécnica de la Universidad de Alcalá de Henares. Ingeniero electrónico y literato. Destacan sus estudios sobre aplicaciones eléctricas y motricidad sobre los que ha publicado varios artículos científicos.

\section{RESUMEN}

Los circuitos eléctricos y electrónicos están formados por elementos activos y elementos pasivos. En este artículo se trata el proceso de fabricación de algunos de estos dispositivos utilizados en dichos circuitos eléctricos, así como sus propiedades. La diversidad de aplicaciones en el campo industrial y de las telecomunicaciones ha hecho que exista un número grande de variantes por cada elemento fabricado. Cubrir todas las necesidades implica el manejo de multitud de características distintas y, en consecuencia, no ha cesado la investigación para aproximarse al funcionamiento ideal en cada ocasión. En este caso nos centraremos en la fabricación de resistencias, condensadores, bobinas y núcleos comúnmente utilizados, transformadores y relés, es decir, los llamados componentes electrónicos pasivos. 


\title{
PALABRAS CLAVE
}

Circuitos eléctricos - Fabricación - Componentes pasivos

\begin{abstract}
Electrical and electronic circuits consist of active and passive elements. This article deals with the manufacturing process of some of these devices in such circuits and their properties. The diversity of applications in industry and telecommunications has made there a large number of variants for each item produced. Cover all requirements involves managing many different characteristics and, consequently, research has continued to approach the ideal performance every time. In this case we will focus on the manufacture of resistors, capacitors, inductors and commonly used cores, transformers and relays, the so-called passive electronic components.
\end{abstract}

\section{KEY WORDS}

Electrical circuits - Manufacturing - Passive components

\section{ÍNDICE}

1. Introducción

2. Resistencias

2.1. Resistencias aglomeradas

2.2. Resistencias de película de carbón

2.3. Resistencias de película metálica

2.4. Resistencias bobinadas

2.5. Resistencias variables

3. Condensadores 


\section{Bobinas \\ 5. Transformadores \\ 6. Relés}

\section{TEXTO:}

\section{Introducción}

En números anteriores se presentó una introducción sobre la implementación semiprofesional de placas de circuito impreso. En esta ocasión, hemos creído pertinente dar a conocer el proceso de fabricación de algunos dispositivos utilizados en los circuitos electrónicos así como sus propiedades. El artículo, dada su extensión, lo dividiremos en varias partes, como viene siendo habitual. En la presente entrega trataremos, breve y someramente, de la fabricación de resistencias, condensadores, bobinas y núcleos comúnmente utilizados, transformadores y relés, los llamados componentes electrónicos pasivos.

Cada uno de los componentes utilizados en los montajes electrónicos tiene características propias, debido a los procesos de fabricación, a los materiales utilizados y al destino práctico que se le va a dar. Desde la invención de los mismos, se ha trabajado para mejorarlos, ampliar su campo de utilización, miniaturizarlos y obtener precios más baratos. Los fabricantes han puesto en marcha los procesos más complicados para obtener estos resultados. Cada uno ha tratado de encontrar la tecnología más adecuada para un mayor rendimiento. Los resultados han sido: la obtención de un gran número de elementos, una gama amplísima de valores en cada uno de ellos, multitud de procedimientos de fabricación, incorporación de los más diversos materiales y obtención de precios relativamente bajos. 
Testimonio fehaciente de esta realidad son los catálogos comerciales. En ellos aparece todo tipo de materiales e información necesaria para un correcto manejo. Son, ciertamente, un medio de publicidad, pero, a la par, los mismos fabricantes están interesados en comunicar los datos técnicos realzando las características de sus productos. Esto hace que no todos los catálogos alcancen el valor técnico necesario para el profesional.

La diversidad de aplicaciones en el campo industrial y de las telecomunicaciones ha hecho que exista un número grande de variantes por cada elemento fabricado. Cubrir todas las necesidades implica el manejo de multitud de características distintas y, en consecuencia, no ha cesado la investigación para aproximarse al funcionamiento ideal en cada ocasión.

\section{Resistencias}

Para conseguir un correcto funcionamiento, las resistencias fijas (de un valor concreto) deben poseer una serie de características que el fabricante ha de tener en cuenta, a fin de que en los circuitos cumplan su cometido perfectamente. Las más importantes son:

-Valor y tolerancia: El valor real deberá estar dentro de unos márgenes de tolerancia que el fabricante dará a conocer.

-Potencia de disipación: No se debe sobrepasar el estipulado por el fabricante, por el riesgo de destrucción y la consiguiente avería en el circuito. 
-Estabilidad: Con el transcurso del tiempo de funcionamiento, el valor nominal se debe mantener dentro de los márgenes que establecen las normas y que el fabricante debe dar.

-Tensión máxima: Además de la máxima potencia de disipación, éste es, obviamente, otro factor que limita el uso de las resistencias, puesto que, si se sobrepasa, se produce un aumento de corriente que conlleva su destrucción.

Otras consideraciones a tener en cuenta son: variación del valor óhmico por aumento de la temperatura, frecuencia de trabajo y/o nivel de ruido.

Según su fabricación, las resistencias se clasifican en diferentes grupos.

\subsection{Resistencias aglomeradas}

La mezcla resistiva se compone de grafito (o carbón) resina y, en algunos casos, talco. Esta mezcla, en proporciones adecuadas, forma un polvo negro que se comprime hasta darle forma cilíndrica. Conseguida ésta, se pasa por un horno y la acción del calor le proporciona dureza. Los termínales se pueden unir a la resistencia, por varios sistemas:

-Arrollando el hilo del terminal a los extremos de la resistencia, a los que previamente se les ha impregnado con una capa de metal pulverizado, y soldándolos a continuación: 


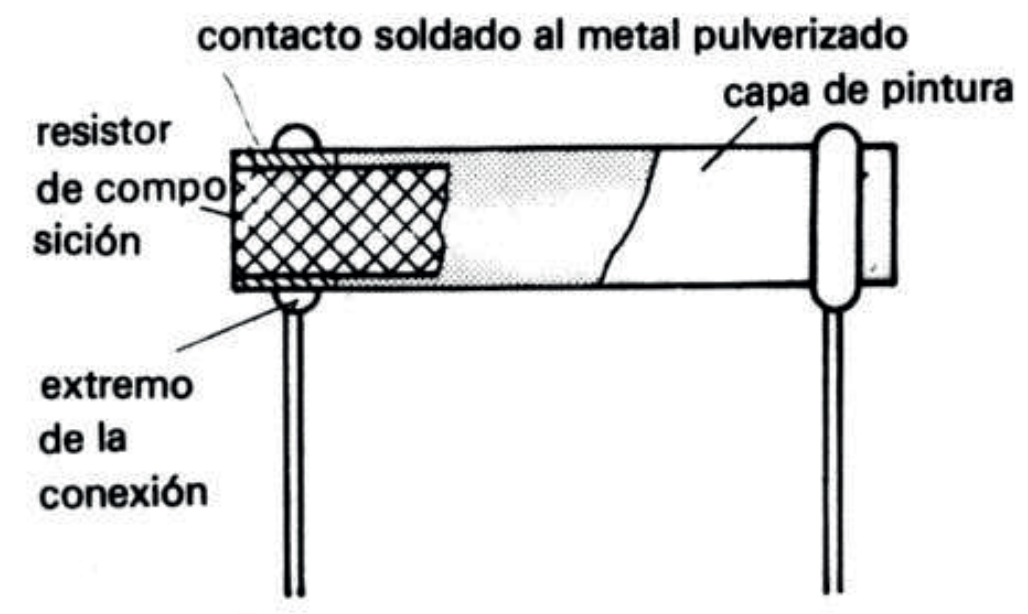

-Colocando en el interior de la mezcla, y antes de ser endurecida, los terminales:

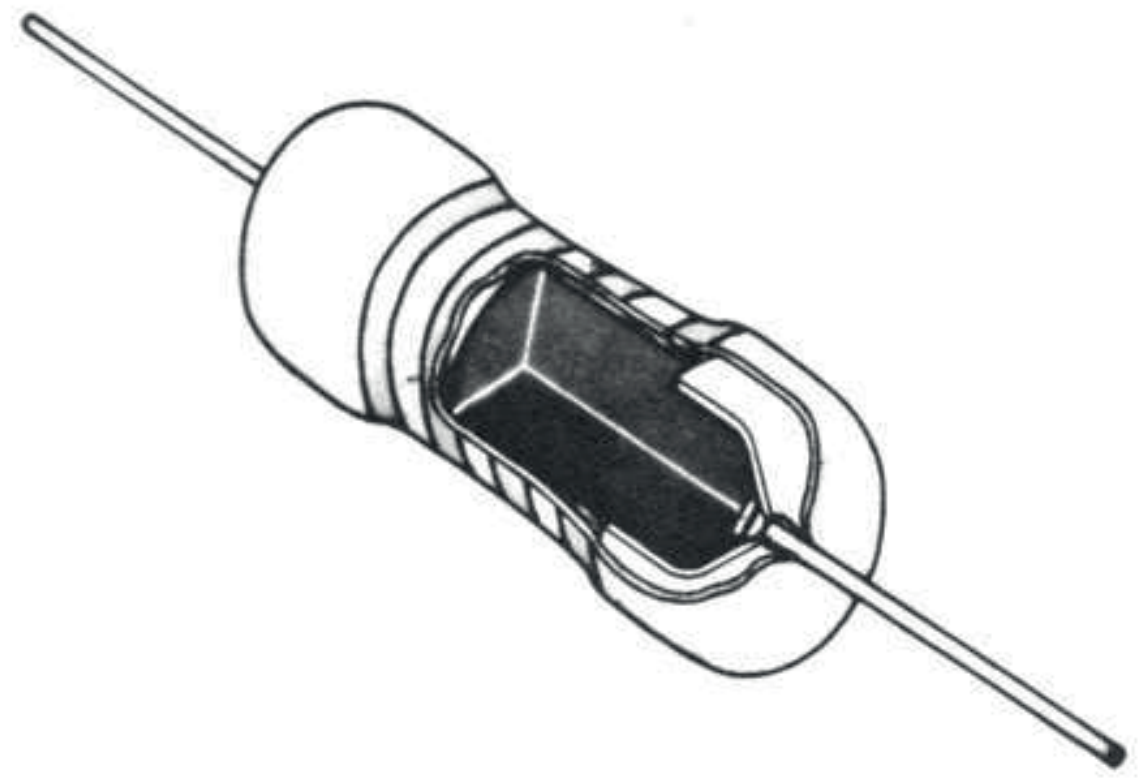

-Colocando unos casquillos metálicos, que ya llevan los hilos de conexión soldados a ellos: 


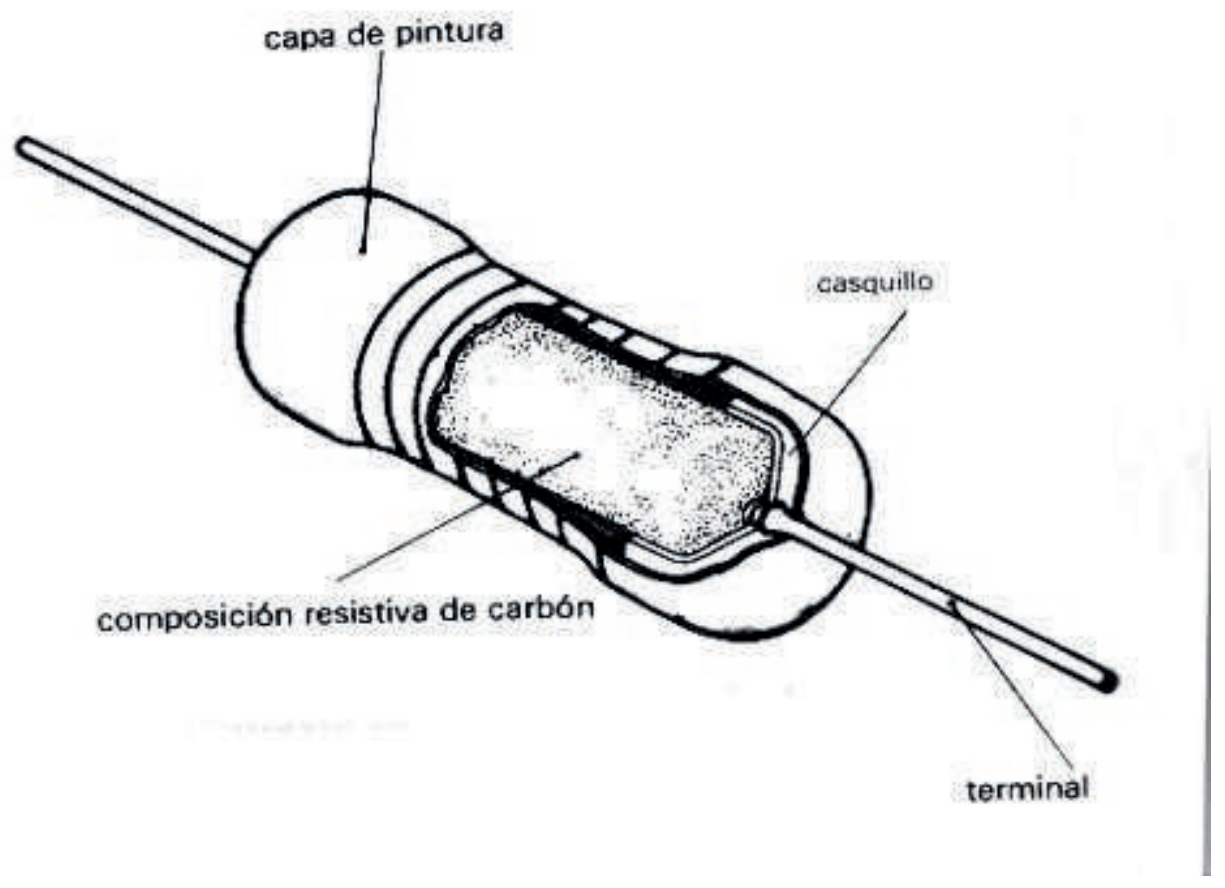

A continuación se impregnan con una capa de barniz o resina protectora y otra de pintura, sobre la cual se indica su valor. Este tipo de resistencias presenta elevada inestabilidad térmica, lo que provoca aumentos en los valores óhmicos con la temperatura de trabajo. Otro "fallo" puede producirse en los terminales, que, al no estar convenientemente sujetos, producen fácilmente cortes en los circuitos o altos niveles de ruido.

\subsection{Resistencias de película de carbón}

Sobre una barra de cerámica se deposita una capa de carbón mediante la descomposición de un vapor de hidrocarburo a temperatura de unos $1000{ }^{\circ} \mathrm{C}$. El valor óhmico se logra mediante el control de la presión, la temperatura y el tiempo de exposición: 


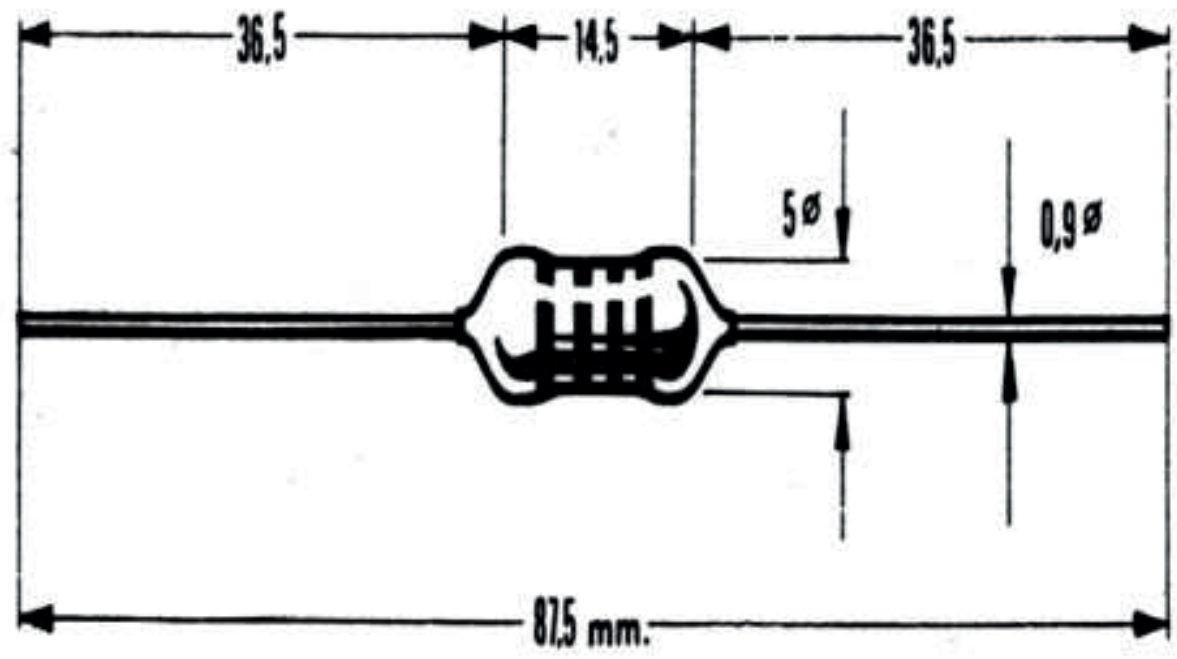

Puede, más tarde, aumentarse el valor realizando un tratamiento especial en la película:

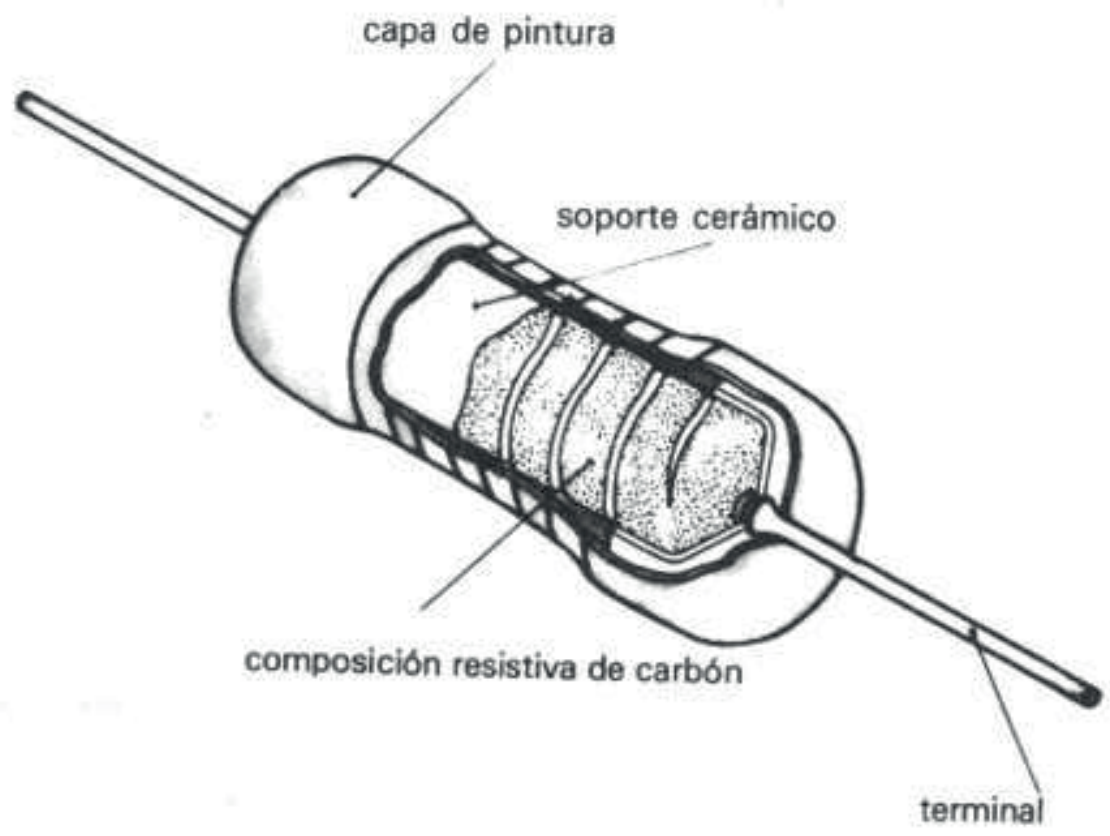

A continuación, se introducen los terminales y se recubren (por moldeo) con una capa de esmalte y pintura, sobre la que se indica el valor óhmico. Su estabilidad es 
mayor que la de las aglomeradas, pero pueden presentar el mismo tipo de problemas anteriormente comentados.

\subsection{Resistencias de película metálica}

El proceso de fabricación es prácticamente el mismo, salvo que, sobre la barra de cerámica, se deposita un metal, en vez de carbón. Ganan en estabilidad a las anteriores y se emplean cuando es necesaria una gran seguridad de funcionamiento o frente a condiciones muy adversas.

\subsection{Resistencias bobinadas}

Existe gran variedad en la fabricación de este tipo de resistencias, tanto por la manera de devanar el hilo, como por la de protegerlo. Es muy interesante que disipen calor con facilidad pues, generalmente, se usan en circuitos en los que la potencia es elevada. No precisan, en cambio, gran exactitud. El hilo se arrolla de manera que la resistencia no presente autoinducción, y para ello, se usa cualquiera de los tres sistemas de la figura siguiente:

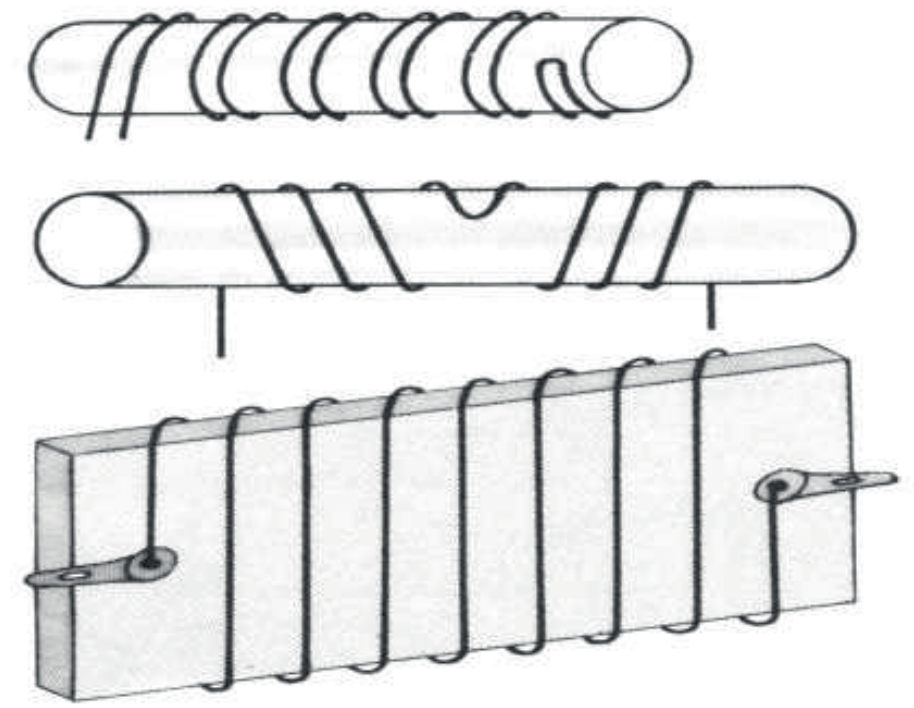


En algunos casos, el hilo no se recubre con ningún material, sino que va colocado sobre un tubo cerámico, en el que se ha practicado una hendidura helicoidal, sobre la que se aloja el hilo. Pueden llevar tomas de corriente, tal y como se aprecia a continuación:

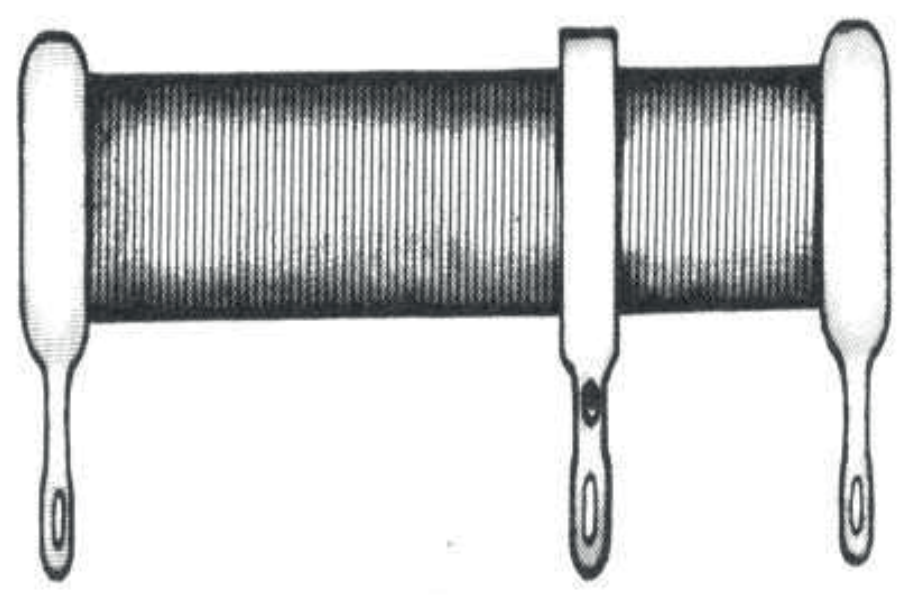

Las que llevan protección son las vitrificadas y cementadas. Las primeras se recubren, una vez bobinadas, con una capa de esmalte vitrificado, cuyo coeficiente de dilatación es el mismo que el del tubo cerámico; el esmalte vitrificado es neutro respecto del hilo (no le ataca) y, además, disipa fácilmente el calor:

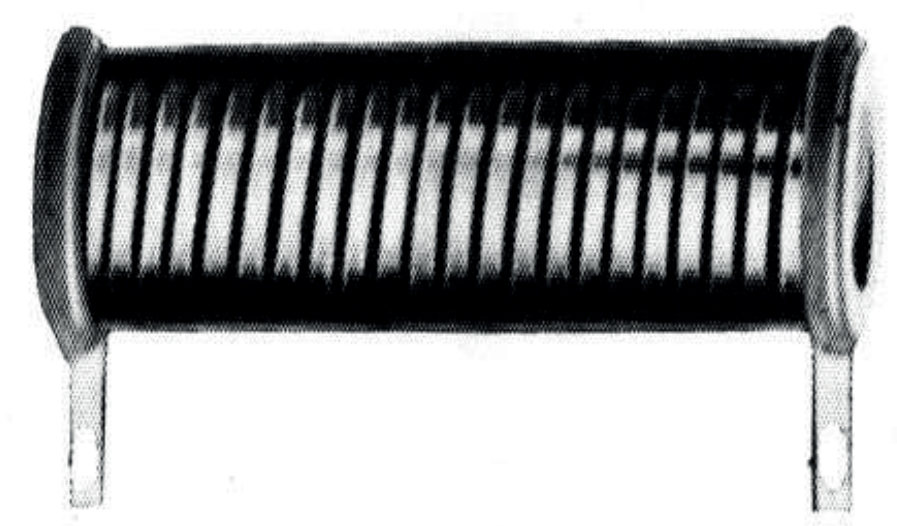


Pueden fabricarse también con tomas de corriente, mediante terminales como los que se muestran en la siguiente figura:

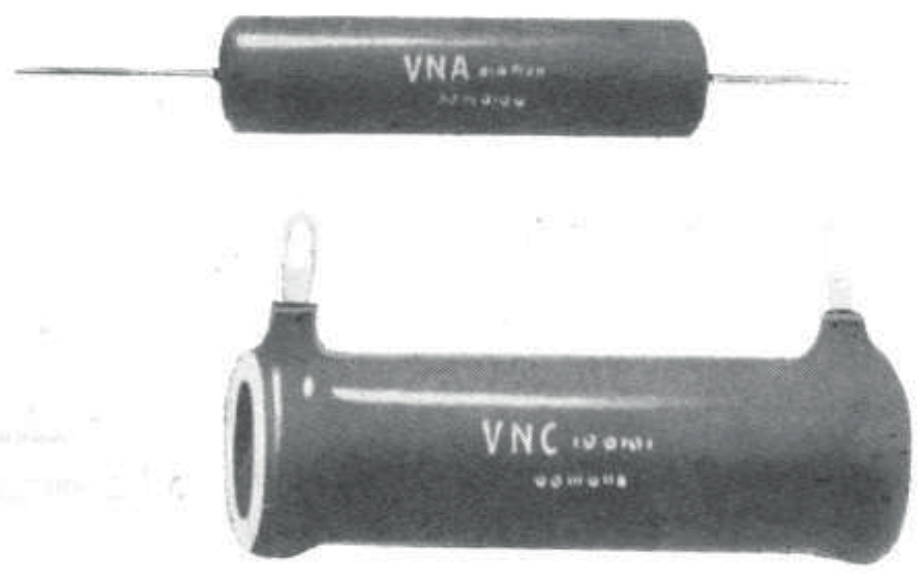

El hilo se suelda a los terminales y, a continuación, se esmalta todo el conjunto en un horno a unos $780^{\circ} \mathrm{C}$, quedando así el bobinado y las conexiones de los terminales totalmente protegidos. Los terminales se deben limpiar antes de su uso. Las vitrificadas con tomas de tensión van libres de esmalte a lo largo de una generatriz, sobre la que se desplaza un collar, que se ajusta mediante un tornillo.

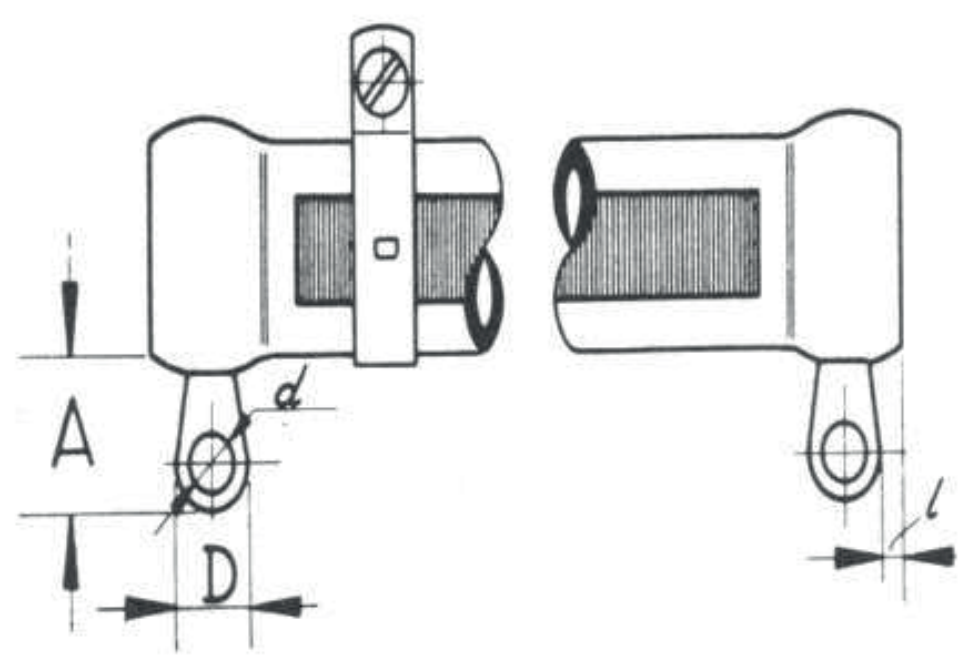


Las cementadas, aún sin alcanzar ni el grado de precisión, ni calidad de las anteriores, cumplen debidamente su función en circuitos de poca precisión. El cemento que recubre el hilo es de naturaleza inorgánica, a base de resinas de siliconas, y puede trabajar a temperaturas de $275^{\circ} \mathrm{C}$. Su fabricación es idéntica a las vitrificadas hasta la impregnación que, en esta ocasión, se efectúa por inmersión de la resistencia en cemento secándolo posteriormente en una estufa de polimerización a temperaturas de $300^{\circ} \mathrm{C}$. Finalmente se limpian los dos terminales y quedan listas para el uso:
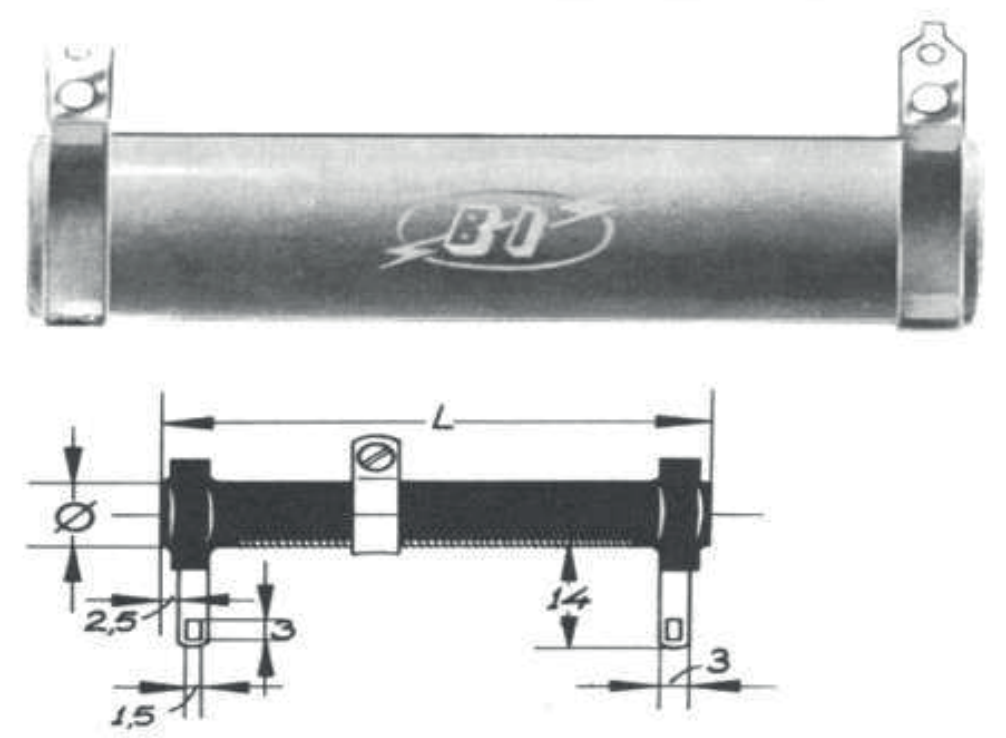

\subsection{Resistencias variables}

Las resistencias variables se clasifican por sus características. Las más importantes son: valor en ohmios, tamaño, ley de variación (lineal, logarítmica, antilogarítmica, etc.), tolerancia, resistencia de aislamiento, potencia a disipar, tensión máxima de funcionamiento, resistencia efectiva mínima y ángulo de giro. 

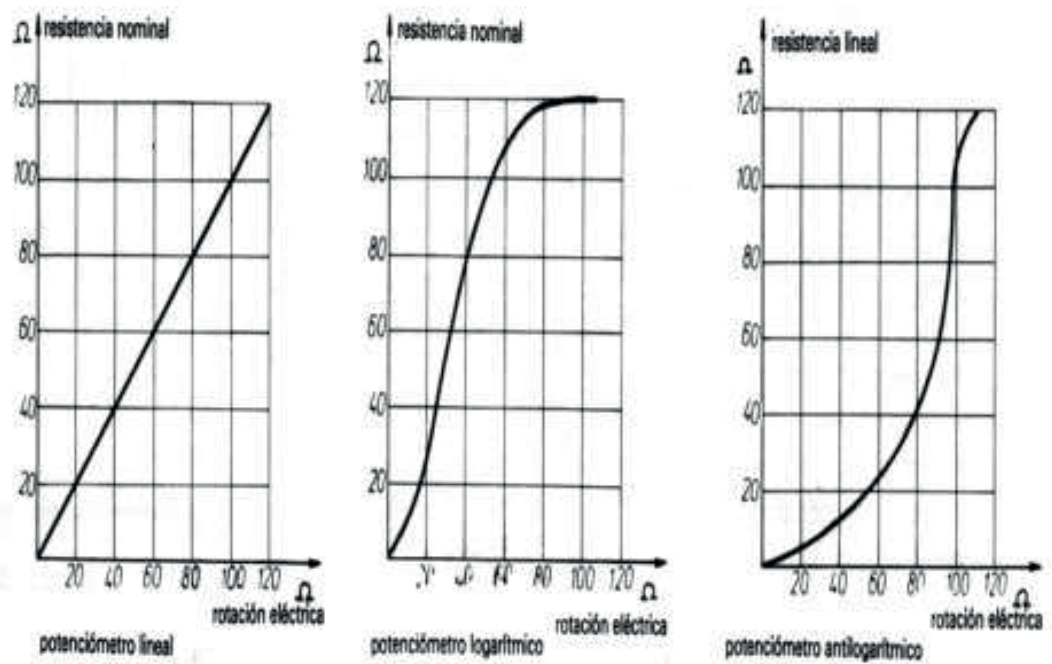

Los hilos de que están fabricadas deben tener uniformidad de diámetro, de resistividad, de resistencia a la tracción y bajo coeficiente de fricción. Si, en vez de bobinadas son de composición, deben reunir también las aludidas condiciones. Sobre el hilo o la pista de composición se desplaza un contacto, que puede tener diversas formas:
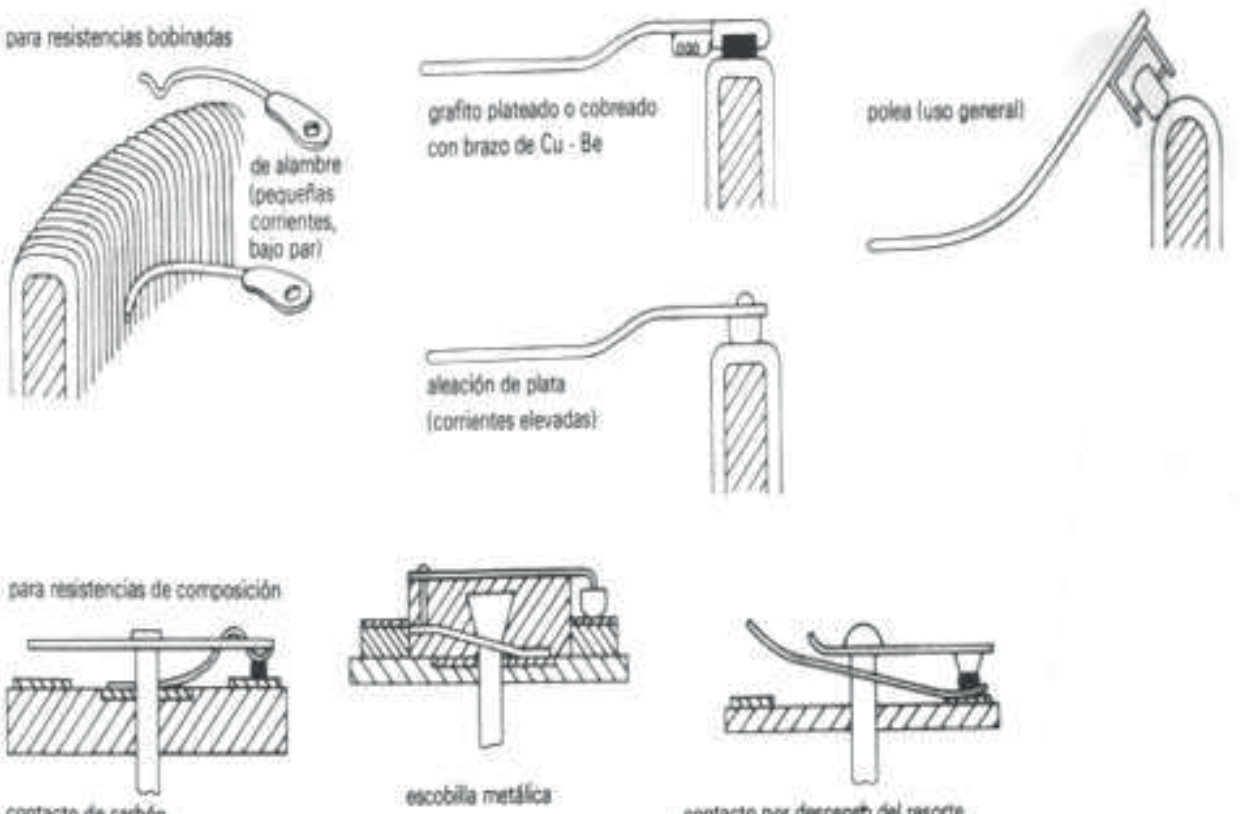

contacto por descansto del tasconte anular en la pesición del brazo asiado 
Sus características fundamentales son baja resistencia de contacto y elevada dureza frente al desgaste. El método de fabricación por composición consiste en depositar una capa de polvo de carbón sobre una banda de plástico fenólico que, sometida a un tratamiento térmico, elimina la fase líquida y fija el valor de la resistencia. A continuación, por estampación, se cortan las pistas para el dispositivo. El proceso se puede esquematizar así:

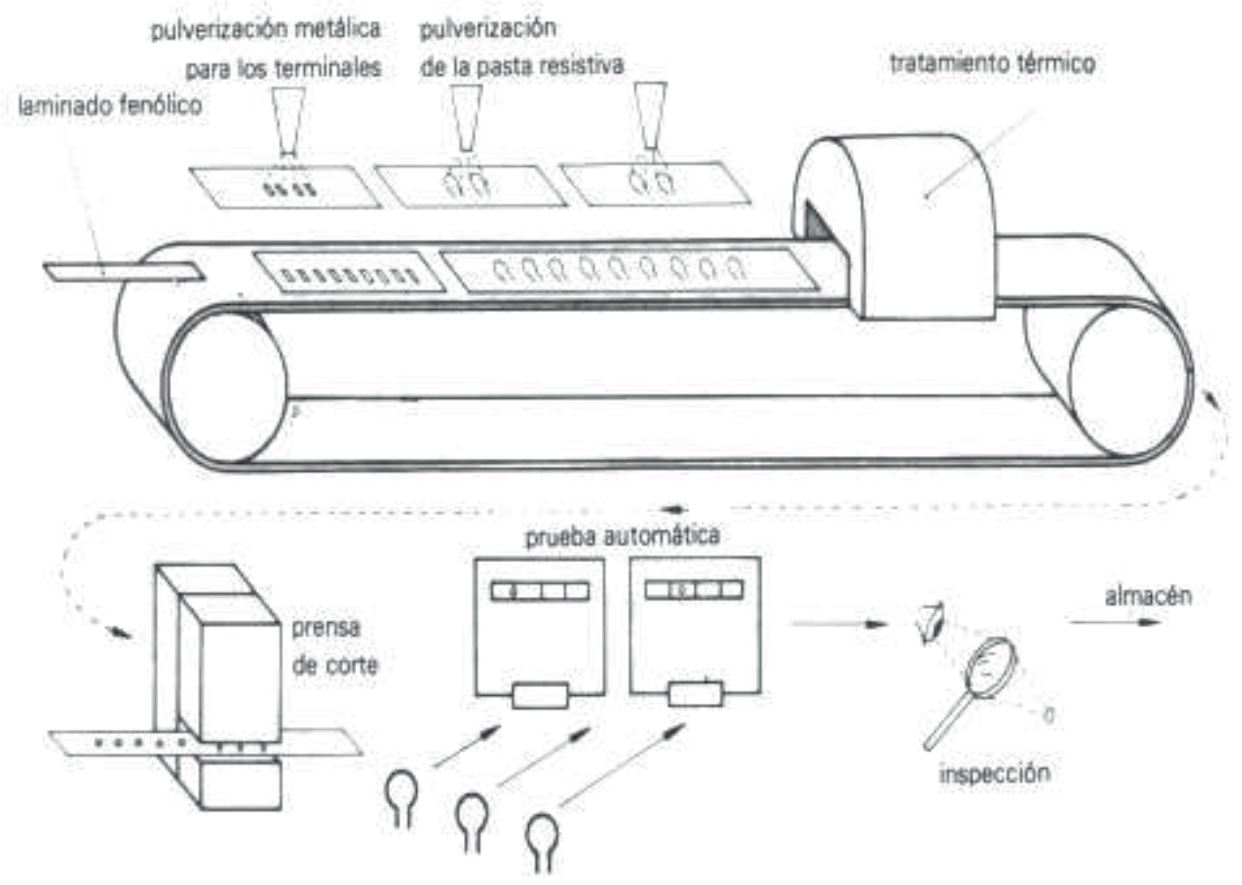

Se dota a estas pistas de dos terminales laterales correspondientes a los extremos de resistencia y el control al contacto del cursor rotativo. También pueden estar provistos de una toma intermedia para ciertos valores y aplicaciones. El cursor establece contacto sobre la resistencia y es accionado por medio de un eje metálico. Todo el conjunto está montado dentro de una caja metálica, que lo protege: 


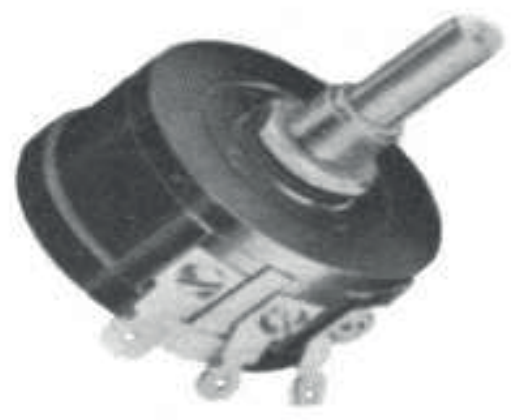

Para la fabricación se han previsto algunas variantes como las que a continuación se muestran:
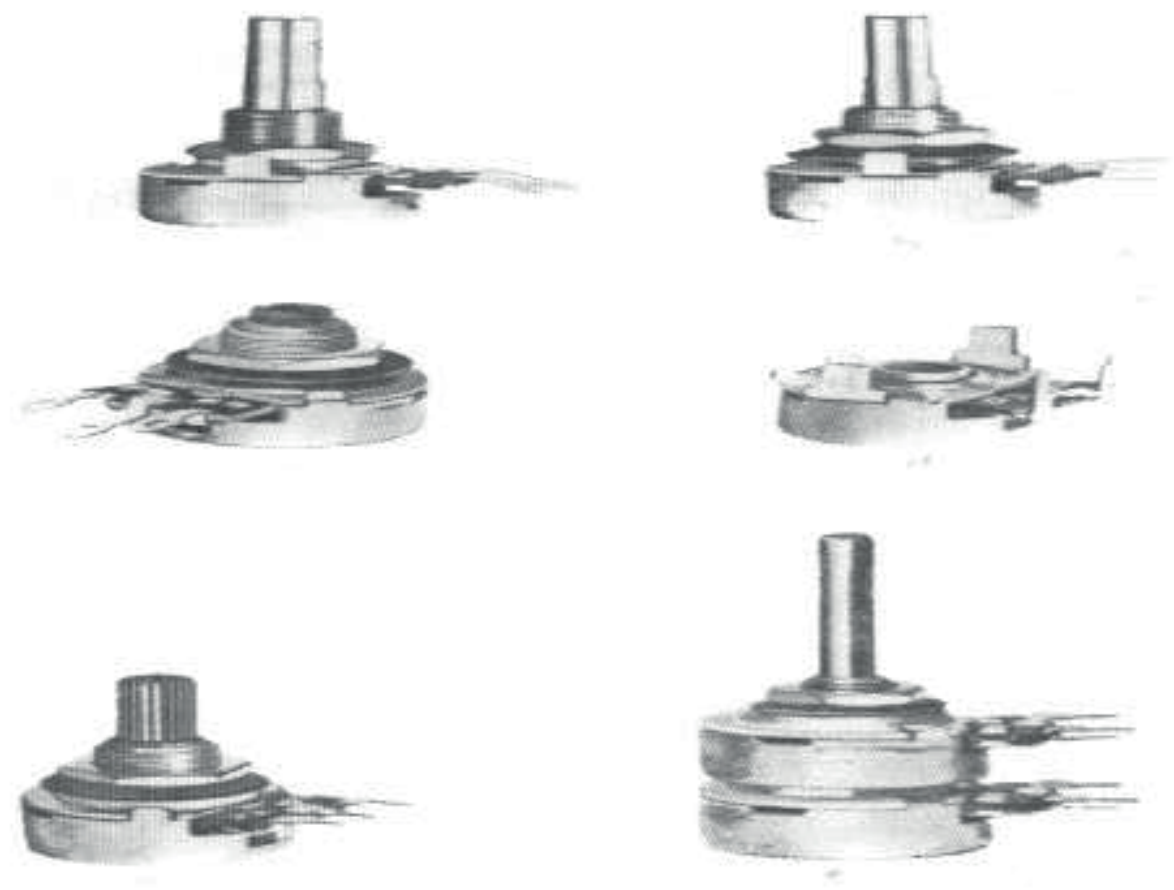

Los potenciómetros ajustables tienen la misma constitución que los anteriores, salvo que el contacto central posee una hendidura, para efectuar posteriores regulaciones, con ayuda del destornillador. Las variantes más comunes son: 
-Con terminales para circuito tableado:

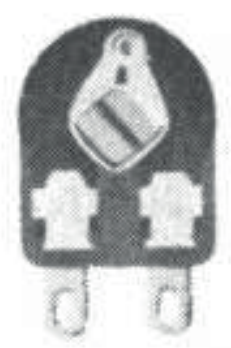

-Con terminales para circuito impreso en montaje vertical:

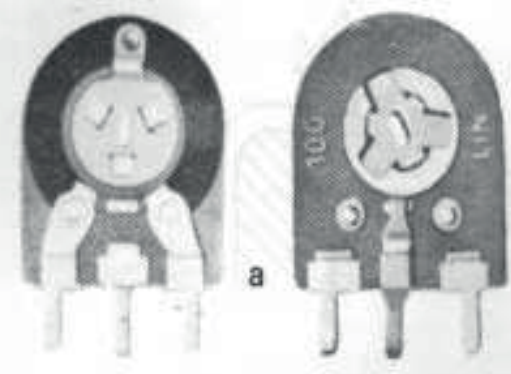

-Con terminales para circuito impreso en montaje horizontal:

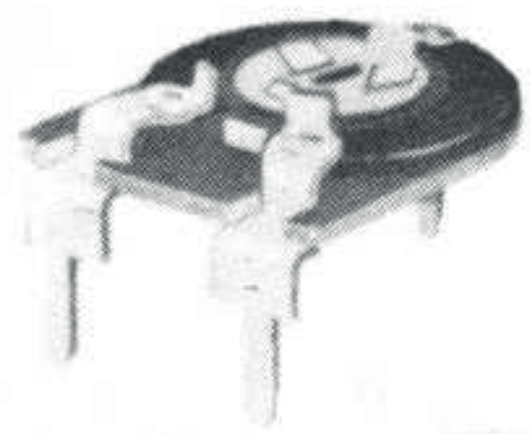

En algunos casos se dota al contacto central de un eje de plástico, en longitud estándar de $18 \mathrm{~mm}$, con su extremo moleteado y una hendidura para accionarlo con el destornillador: 


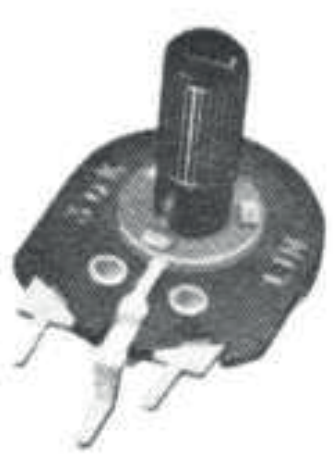

\section{Condensadores}

Los condensadores se agrupan por su fabricación (constitución del dieléctrico) y aplicaciones. Los materiales más utilizados en la manufactura de estos dispositivos son: mica, vidrio, porcelana, papel, película de óxido, polietileno y poliestireno. Todos ellos cumplen idénticas funciones y sólo sus características los diferencian. Éstas se deben tener en cuenta, según el trabajo que vayan a desempeñar en los circuitos. Para su elección se tendrán en cuenta los datos siguientes:

Capacidad, tensión nominal, tensión de servicio, intensidad que circula, temperatura ambiente de funcionamiento, espacio disponible, toma de fijación, factor de pérdida y corriente de fugas.

Por la naturaleza del dieléctrico se clasifican en:

-De papel:

Construidos con dos cintas de aluminio, entre las que se interpone un dieléctrico estratificado de papeles de Kraft, bobinándose todo ello de forma que su inductancia sea mínima. Esta bobina se impregna cuidadosamente en un doble proceso de temperatura y vacío. El impregnante consiste en vaselinas o ceras especiales: 


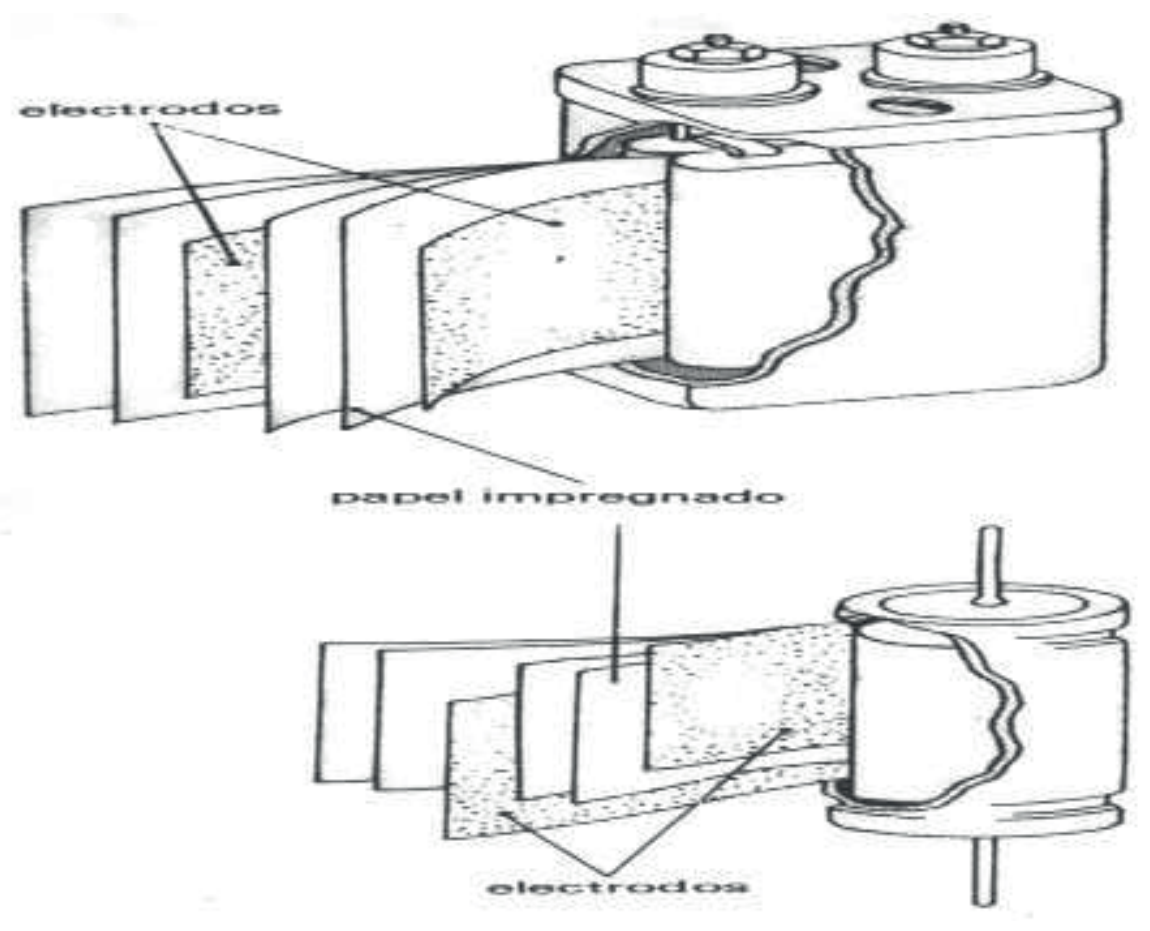

Tienen elevada relación capacidad/volumen y funcionan con tensiones elevadas.

-De papel metalizado:

Consiste en metalizar el papel por una cara con una fina capa. Así se suprimen los espacios vacíos entre placas y dieléctrico, obteniéndose una capacidad igual a la de los anteriores, con menor volumen. No mantienen el cortocircuito, caso de producirse, ya que el metal se vaporiza en el lugar donde se produzca la perforación del dieléctrico, no alterando su capacidad.

\section{-Cerámicos:}

Suelen fabricarse utilizando composiciones de óxidos metálicos (silicato magnésico, dióxido de titanio, dióxido de circonio) que, mezclados con caolín, feldespato y bentonita se someten a cocción, con la que se obtiene una pasta con características de elevada permeabilidad y, por consiguiente, de una elevada capacidad en un tamaño 
reducido. La gama de modelos que se obtienen en este proceso es muy extensa, siendo algunos de ellos:

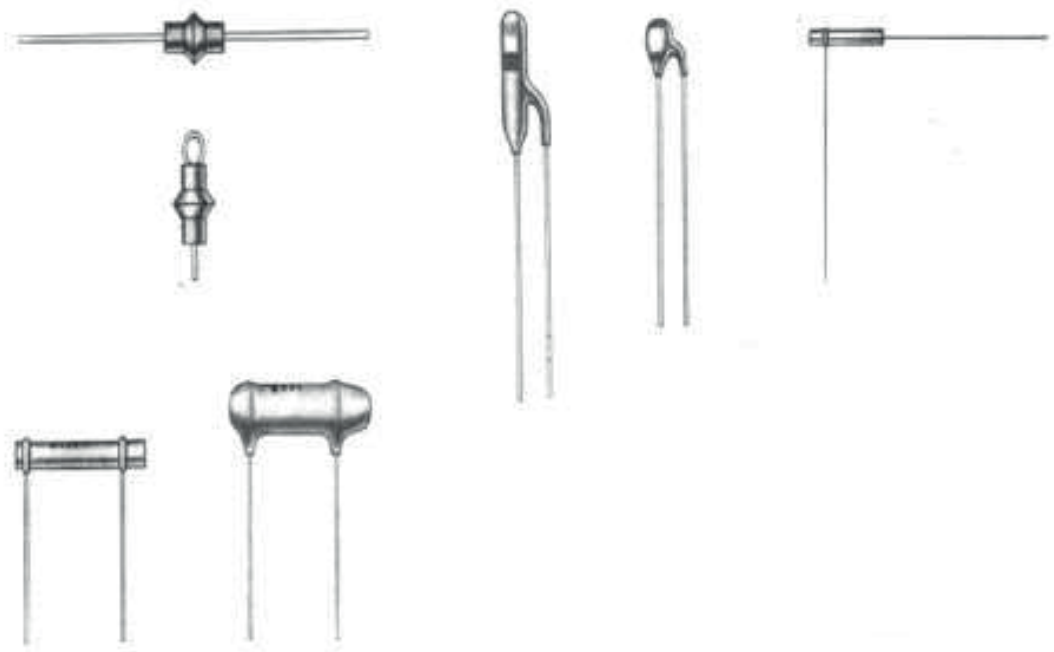

-De poliéster

Están constituidos por dos cintas de aluminio y de poliéster, bobinadas entre sí. Dicho bobinado se efectúa de tal forma que sea anti-inductivo. Se recubren con varias capas de laca, que los hacen inalterables a la humedad. La gama de modelos también es amplia; algunos de ellos aparecen a continuación:
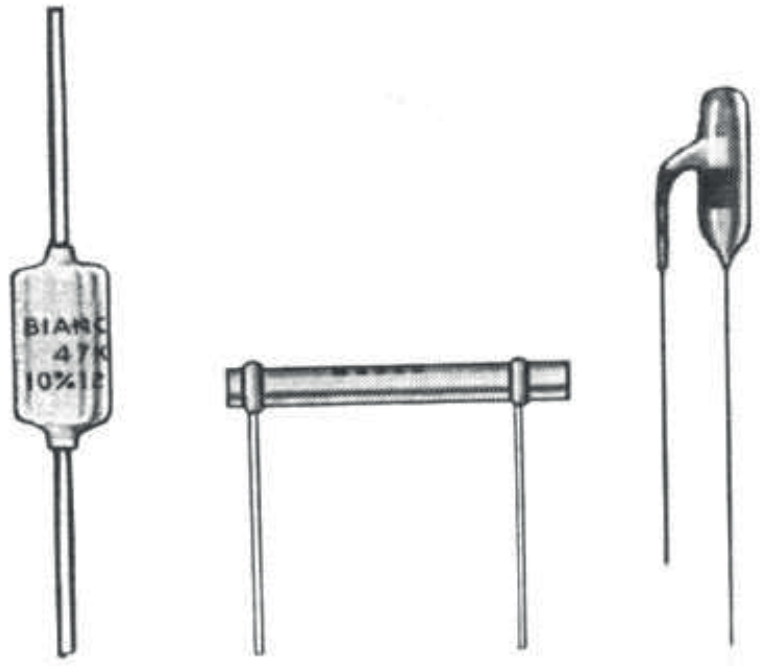
-Electrolíticos:

Tienen como propiedad más importante su gran capacidad para un volumen dado. Están construidos con una placa metálica, cubierta de una capa de óxido muy fina, bañada por un electrólito. Aplicando tensión al conjunto, la capa de óxido se forma por la electrólisis. Entre las dos hojas de aluminio (ánodo y cátodo) está el electrólito (este tipo se llama electrolítico líquido):

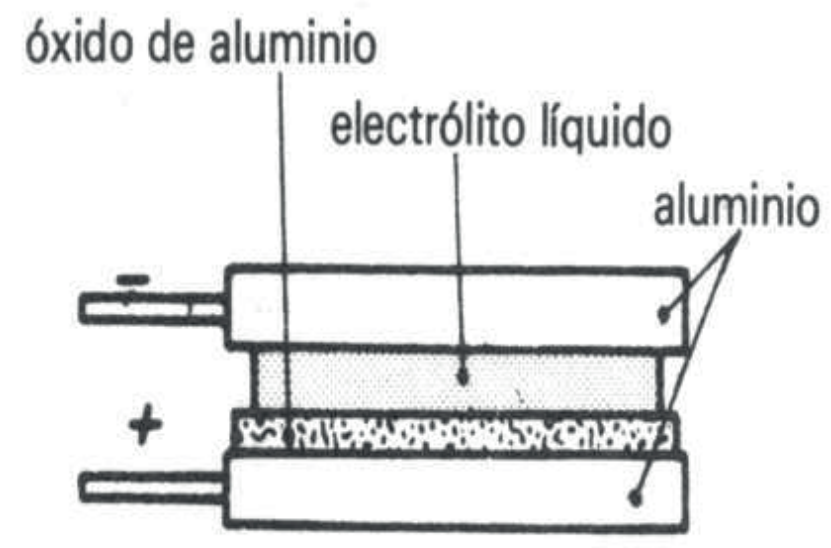

Otros tipos, son el llamado semiseco, que lleva una hoja absorbente entre ambas placas:

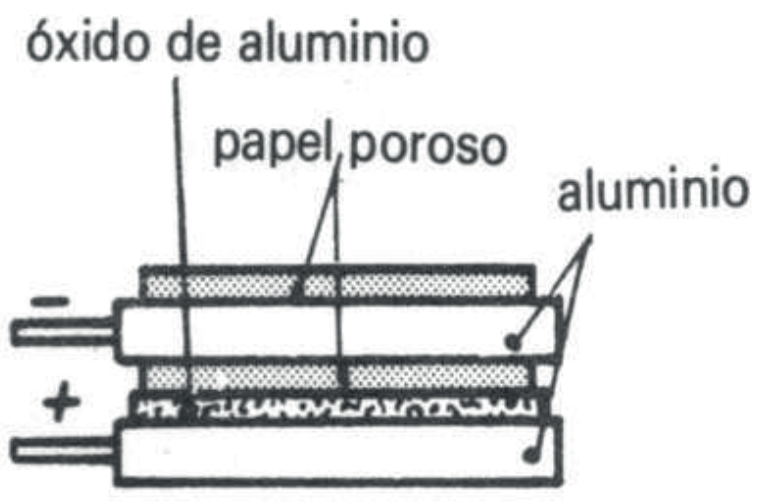


y el seco, que tiene un papel metalizado entre un electrodo y la hoja de aluminio:

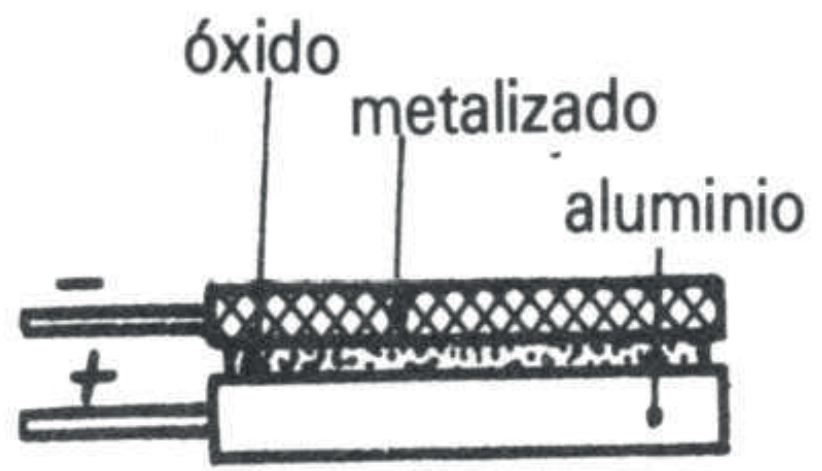

Estos conjuntos descritos se arrollan e introducen en un bote que luego se cierra con un disco de baquelita y/o goma:

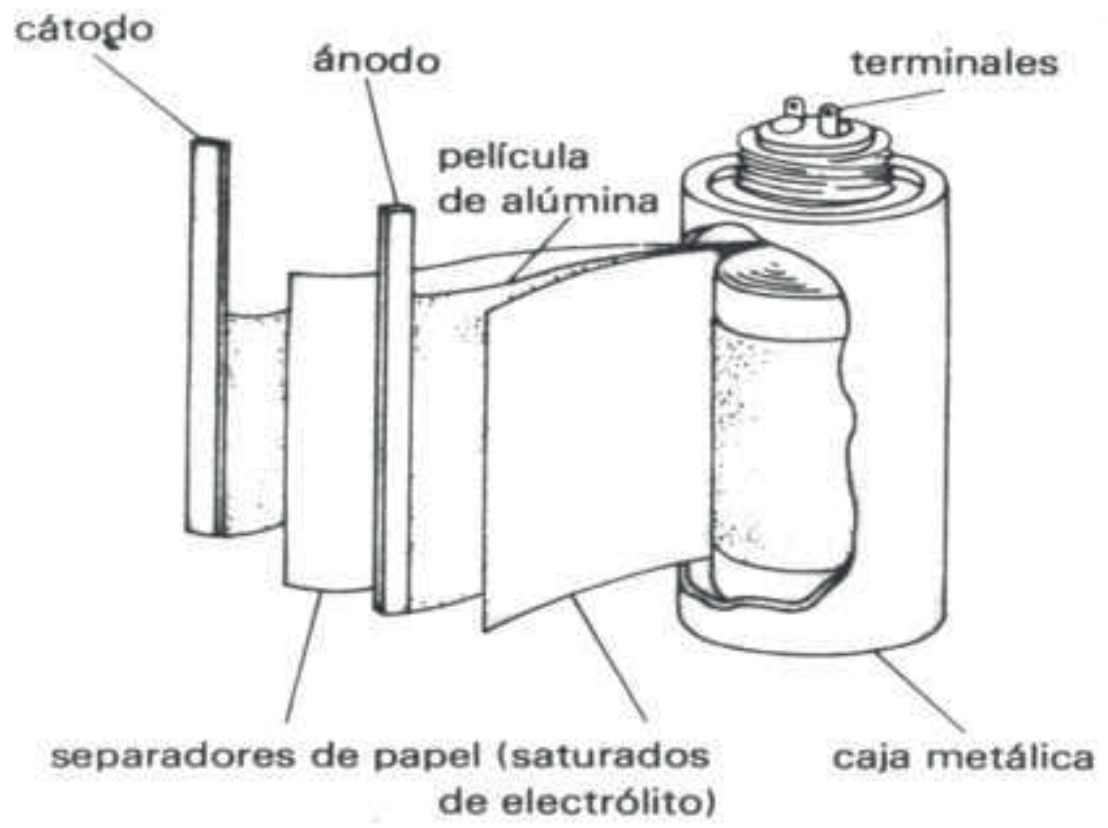

Los así fabricados tienen polaridad fija; pero pueden ser también reversibles. Estos últimos se construyen metalizando entre un electrodo y la hoja de aluminio como se indica aquí: 


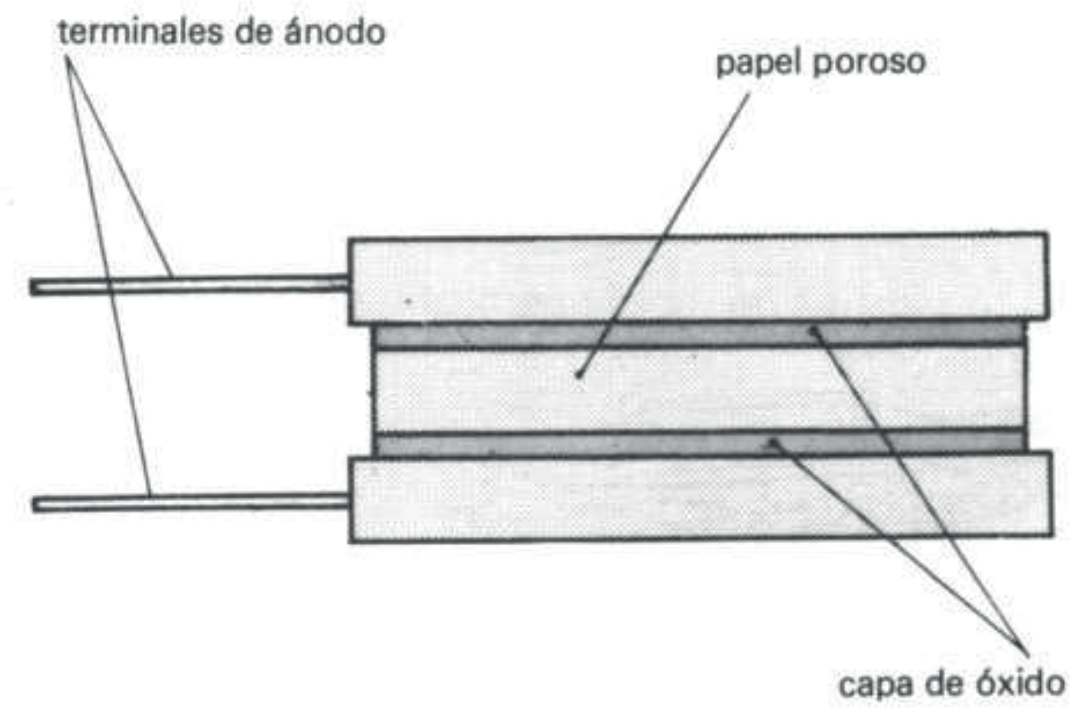

-De mica

La mica es un compuesto de silicato alumínico-magnésico-potásico, con la propiedad de ser muy dúctil y maleable, consiguiéndose láminas muy finas. Éstas constituyen el dieléctrico y las armaduras están formadas por hojas metálicas. Las hojas de metal y de mica se van alternando; se sueldan a una grapa, que sujeta las hojas metálicas pares, con las cuales se forma un electrodo de hilo de cobre; otra grapa sujeta las impares, y con ellas, se forma el otro electrodo. El conjunto así formado se envuelve en cerámica, resinas o esmaltes para protegerlo de los agentes exteriores: 


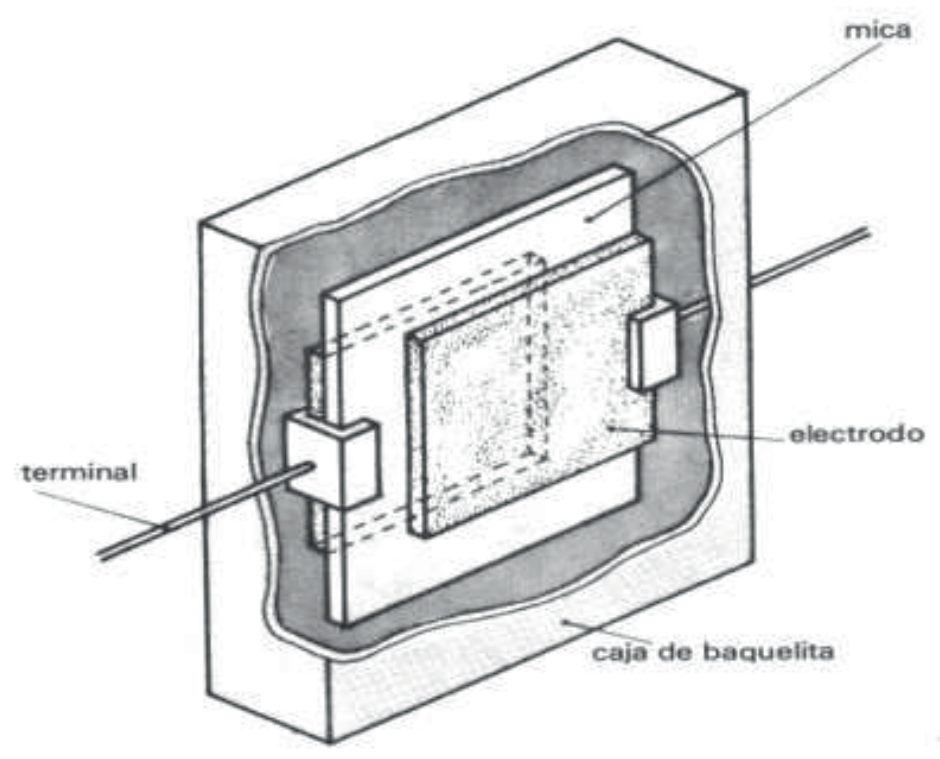

Por último, para los condensadores diremos que, al igual que ocurría con los resistores, también existen variables, mas este es un tema que no tocaremos debido a que este tipo de componentes no es tan habitual como los ya comentados.

\section{Bobinas}

Los circuitos electrónicos precisan, en muchas ocasiones, de los efectos de autoinducción; pero el valor que debe tomar la bobina varía para cada circuito, quedando a merced del resto de los componentes (téngase en cuenta que éstos últimos no están exentos de la inducción). Por ello, no se ha podido estandarizar la fabricación de bobinas; cada fabricante las hace de acuerdo con las necesidades de un circuito determinado, usando los medios que considera más apropiados. La técnica de fabricación es muy variada; pero los materiales utilizados son los mismos para todos. En la mayoría de los casos, lo que se pretende es oponerse a la variación de corriente, importante papel que la bobina cumplirá. Ahora bien, si se encuentra auxiliada por otros materiales y dispuesta de tal modo que ellos puedan influir sobre ella, los resultados pueden ser muy distintos. Las bobinas con núcleo de hierro 
pueden aumentar su efecto de autoinducción, con sólo variar la calidad de éste, o la posición que ocupa dentro de la bobina:

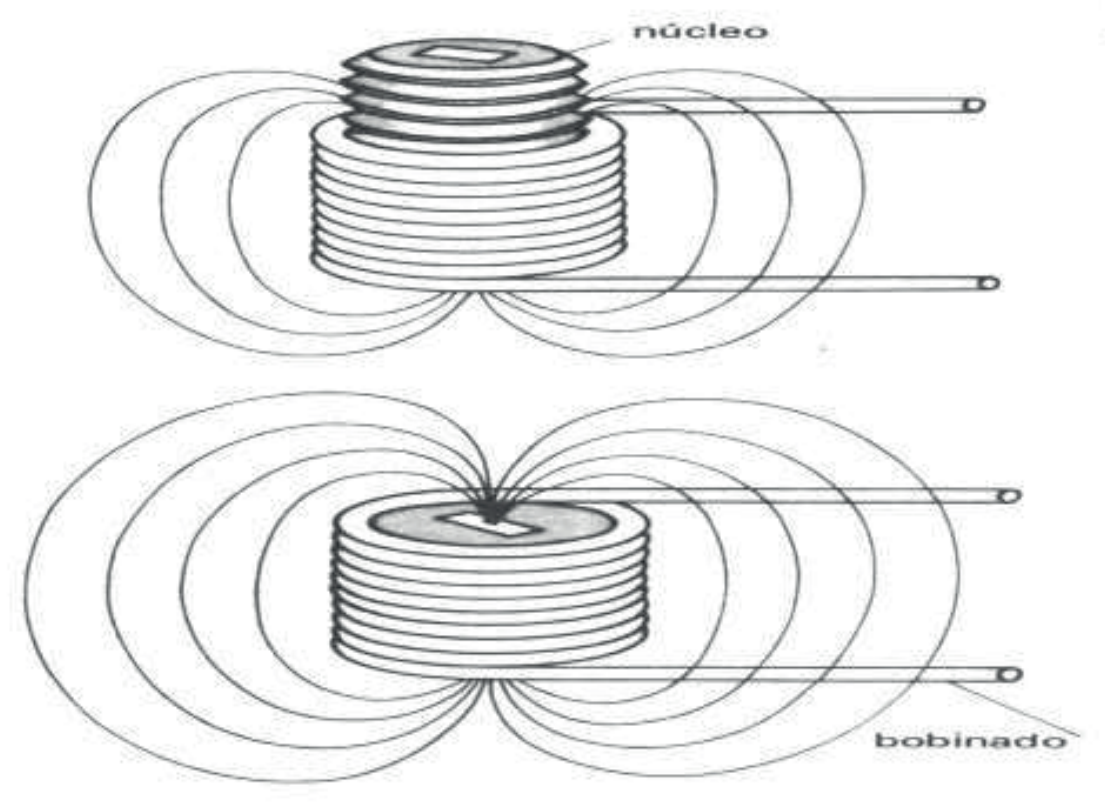

Las que no poseen núcleo de hierro, que suelen ser las usadas en alta frecuencia, se ven afectadas por una serie de cambios respecto de las anteriores, tal como el aumento de la resistencia que lleva consigo la variación del tipo de hilo usado. Algunas bobinas muy comunes son:

-Bobinas de choque para filtro:

Usadas normalmente en el aplanado de la corriente pulsante, salida de la rectificación (de muy baja frecuencia). Su proceso de fabricación se basa en el arrollamiento, sobre un molde de cartón, del hilo de cobre esmaltado. Terminado de bobinar, se introducen las dos chapas magnéticas sujetándolas mediante un sistema mecánico: 


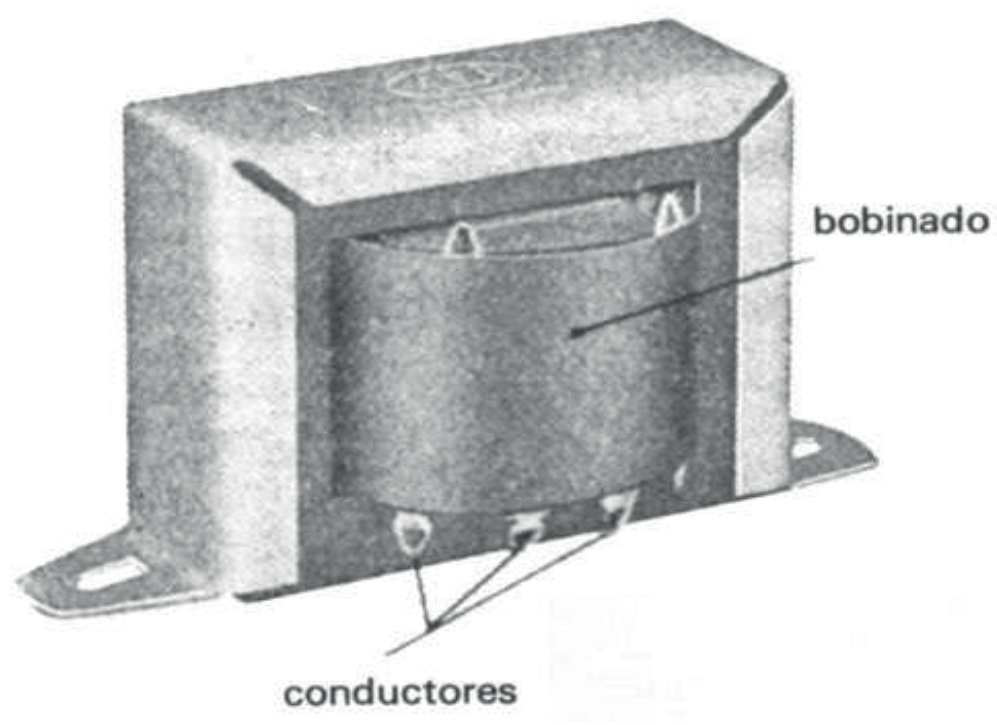

A continuación, pueden apreciarse las chapas del circuito magnético, en forma de "E" e "I", y cómo se agrupan:

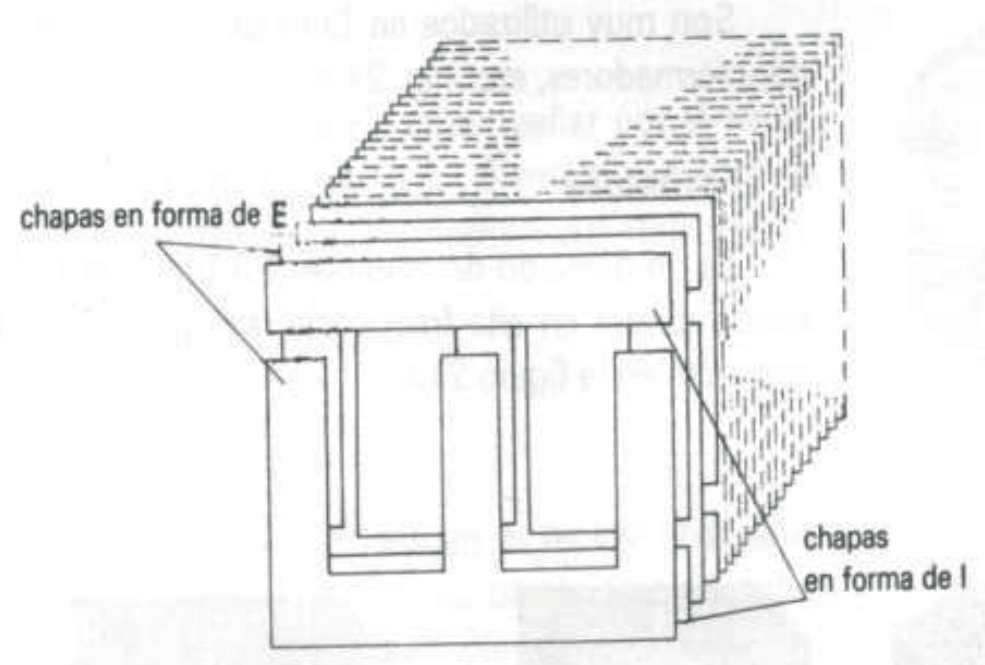

-Bobinas de choque para R.F. (radiofrecuencia):

Al aumentar la frecuencia, para lograr idénticos efectos, el número de espiras no hará falta que sea tan grande. Así resultan unas bobinas de tamaño reducido, como se ve: 

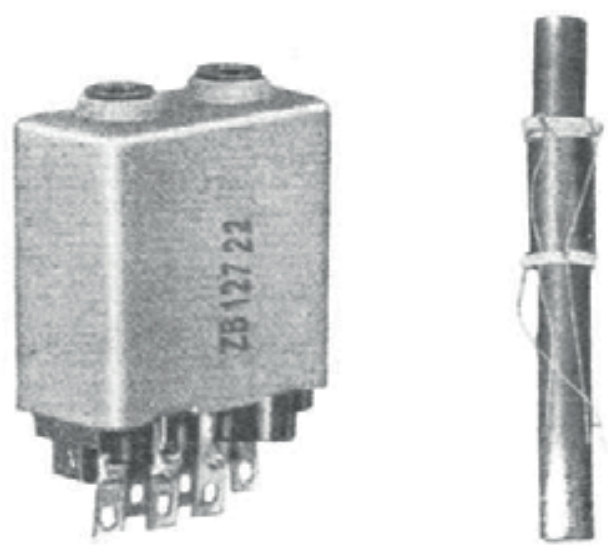

-Núcleos magnéticos

Los núcleos magnéticos más comúnmente usados se citan seguidamente:

1) Latón y cobre: Para selectores de canales y frecuencia intermedia de radio y televisión. Disminuyen la inductancia:
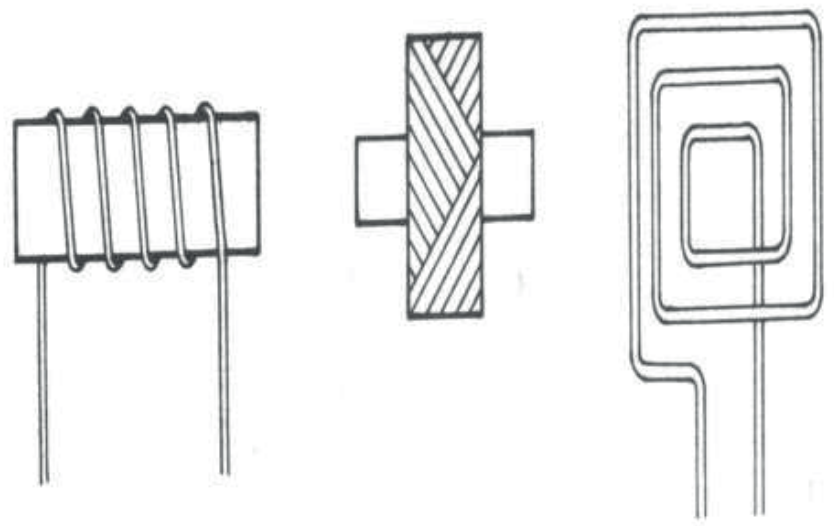
2) Hierro: Generalmente se usa en transformadores, y las chapas toman formas diversas:
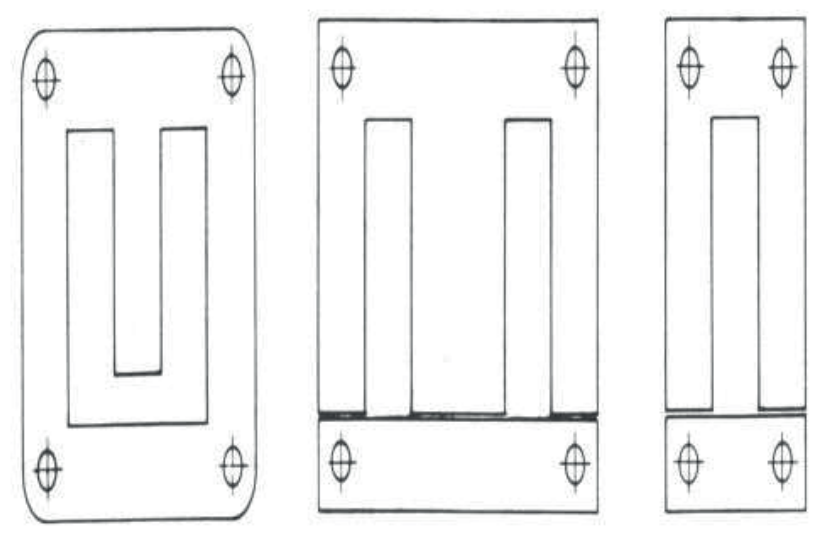

3) Ferritas: Están compuestas de hierro y otro material (cobre, magnesio, plomo, níquel o manganeso). Con tratamientos adecuados, se obtienen coeficientes de permeabilidad muy aceptables. Son muy utilizados en bobinas para antenas, anillos deflectores, cierres magnéticos, transformadores, etc.

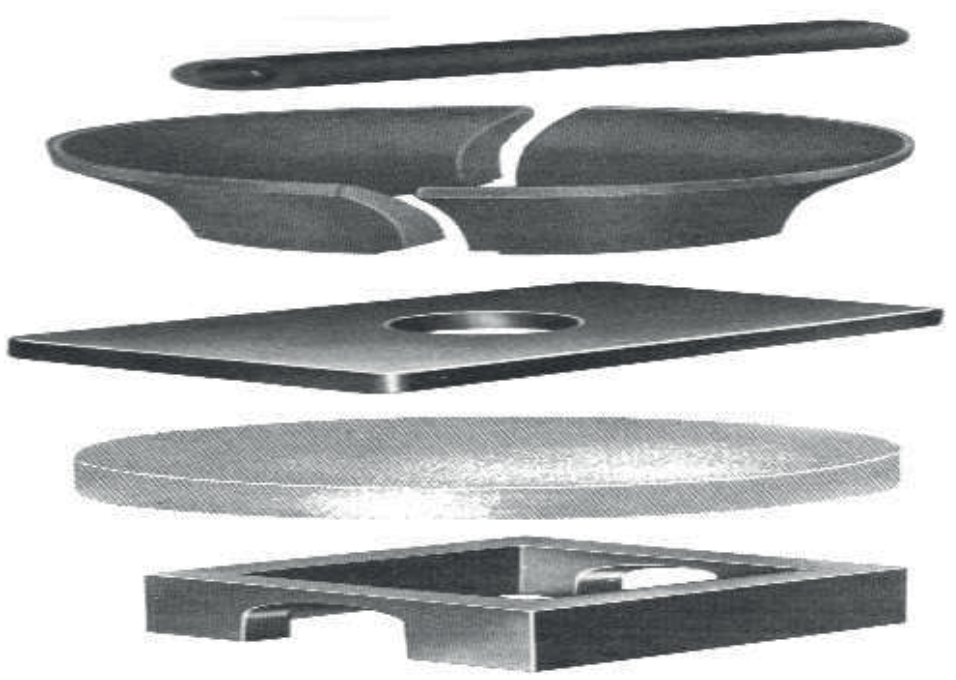


4) Ferroxcube: Es un derivado del anterior. Su principal característica es la de su alta resistividad; se puede utilizar en alta frecuencia, sin que las pérdidas sean grandes. Su forma y tamaños son tales como:

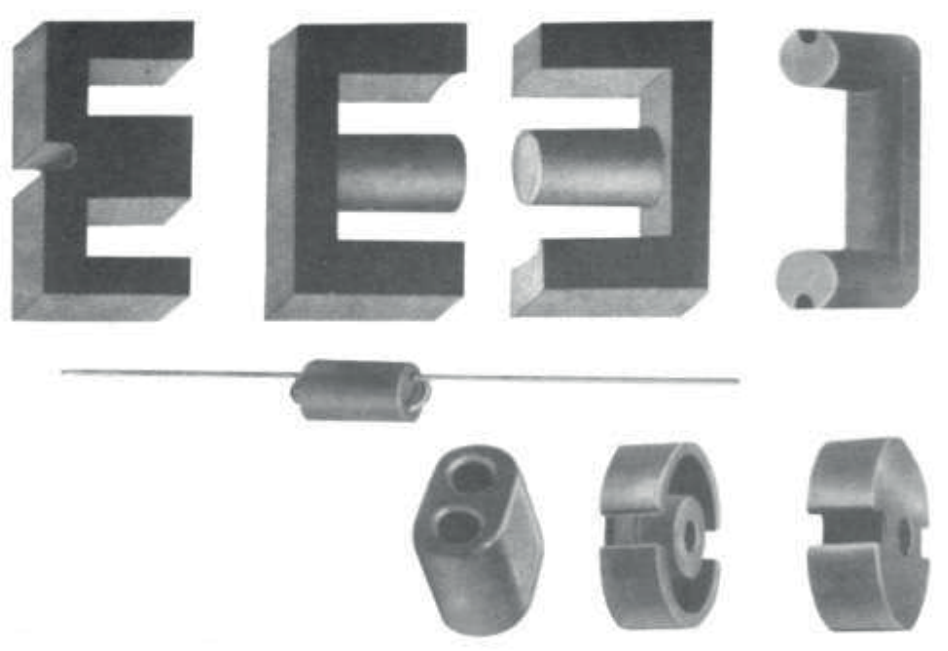

\section{Transformadores}

Como resulta lógico, tras hablar de bobinas, es normal tratar de la fabricación de transformadores. Los dos elementos fundamentales en la construcción de un transformador son: el circuito magnético y los circuitos eléctricos. Teniendo en cuenta que siempre se pretenden los mejores rendimientos, la elección del tipo de circuito magnético se hará atendiendo a su calidad y a su forma. La calidad depende de la composición del material de las chapas (normalmente de hierro) con inclusiones no ferromagnéticas, generalmente de silicio, en los porcentajes apropiados. También las hay con inclusiones ferromagnéticas, generalmente de níquel. Las formas de núcleos más usadas son: 

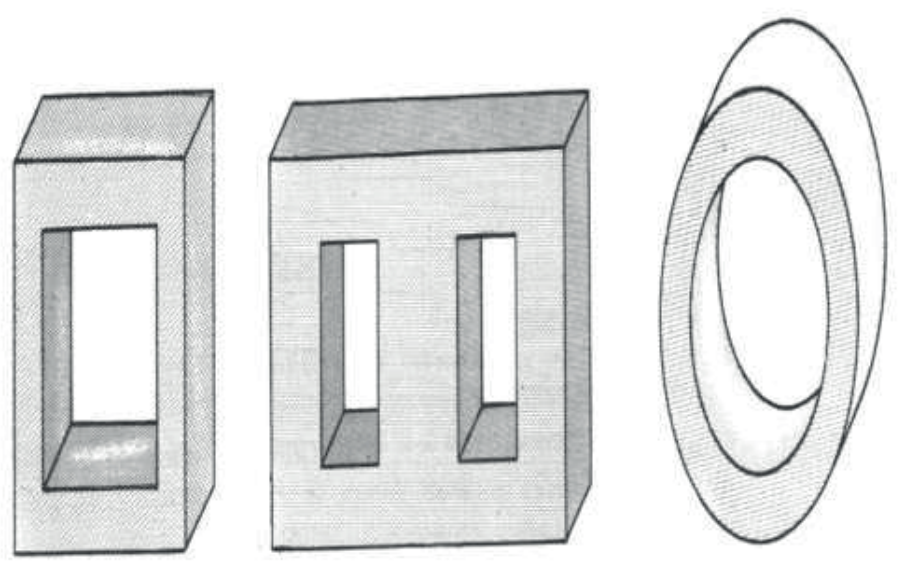

Los bobinados se disponen entre las columnas de la armadura o núcleo. Los tipos de hilo para bobinados varían, según la función que desempeñe; pero, en general, los utilizados son los de cobre y aluminio. Siempre van impregnados con barniz, cuyas características deben estar en consonancia con las normas del Reglamento Internacional Electrotécnico.

\section{Relés}

Tras hablar de bobinas y de transformadores, resulta normal tratar de los relés electro-mecánicos. Estos son dispositivos electromagnéticos que actúan al recibir una señal eléctrica, desplazando "instantánea" o temporizadamente una de sus partes (móvil), cumpliendo, así, cualquier requerimiento de cierre o apertura de sus contactos. Básicamente, todos tienen partes comunes como son: circuito eléctrico, circuito magnético y contactos. El circuito eléctrico puede variar en la forma y el valor de la sección de cobre, aislamiento de espiras, etc.; pero, su función es siempre la de crear un campo magnético que desplace la parte móvil: 


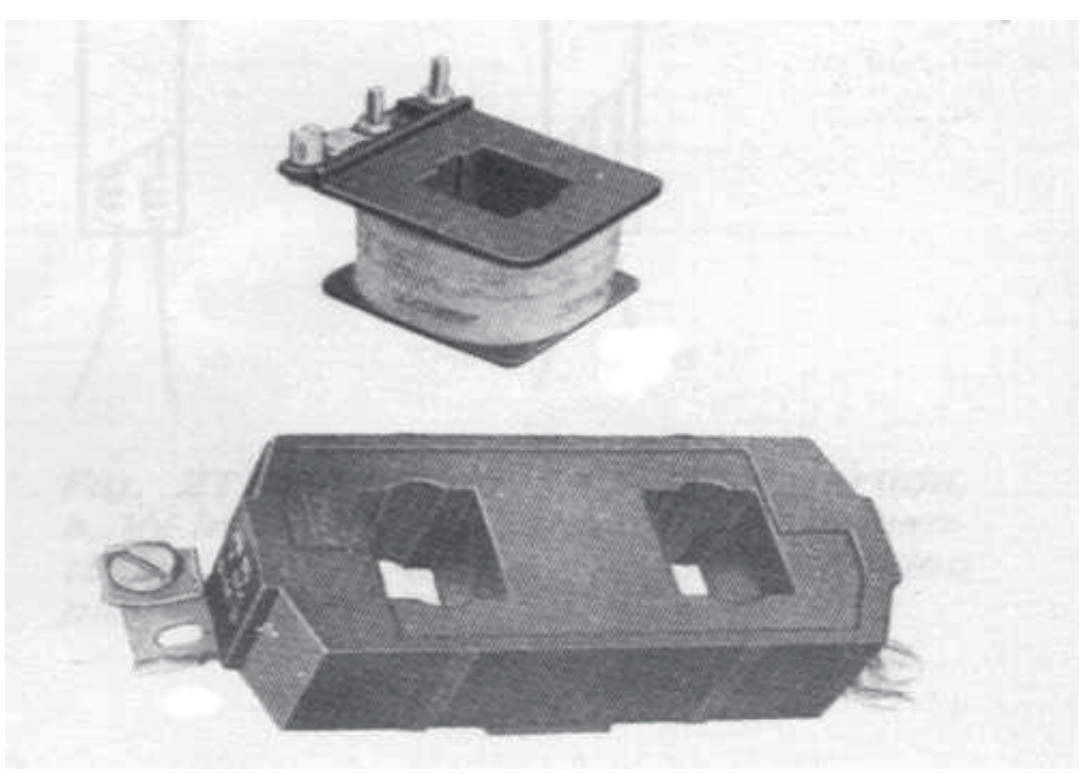

El circuito magnético está compuesto por chapas que forman, junto con la bobina, un electroimán, también de forma determinada:
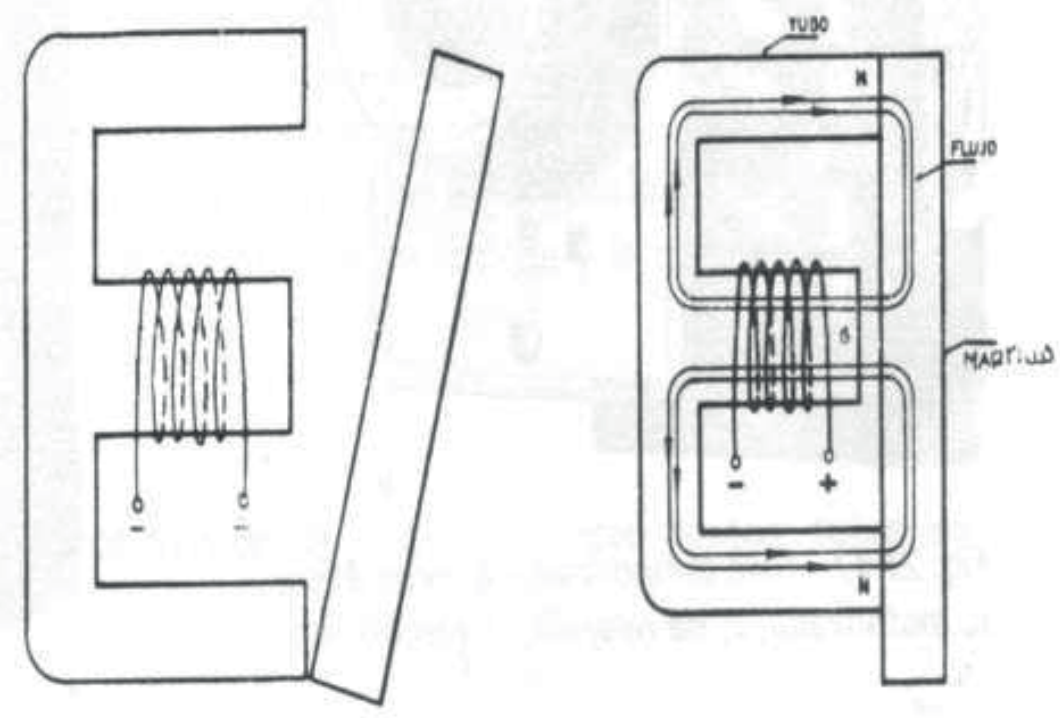

tienen como misión desplazar los contactos que han de abrir o cerrar los circuitos. Los contactos soportan la apertura y cierre de los circuitos y, por acción eléctrica y mecánica, están sometidos al trabajo más duro del reté. Así, pues, la naturaleza de éstos debe ser muy dura y, al mismo tiempo, conductora de corriente (se usan, 
generalmente, aleaciones de cobre y plata con cadmio). También su forma exterior es objeto de estudio. Los más idóneos son los que a continuación se muestran:
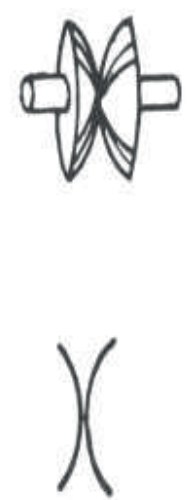
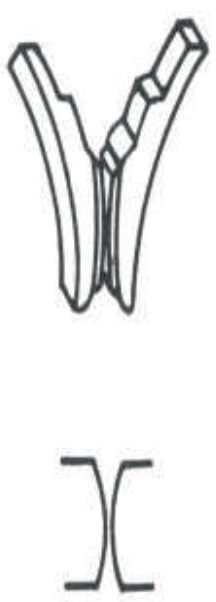
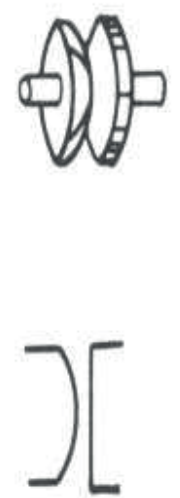

cuya superficie de contacto es muy pequeña, con lo que se aumenta la presión y se disminuye la resistencia eléctrica de la unión. Además del relé normal de maniobra que se ha comentado:
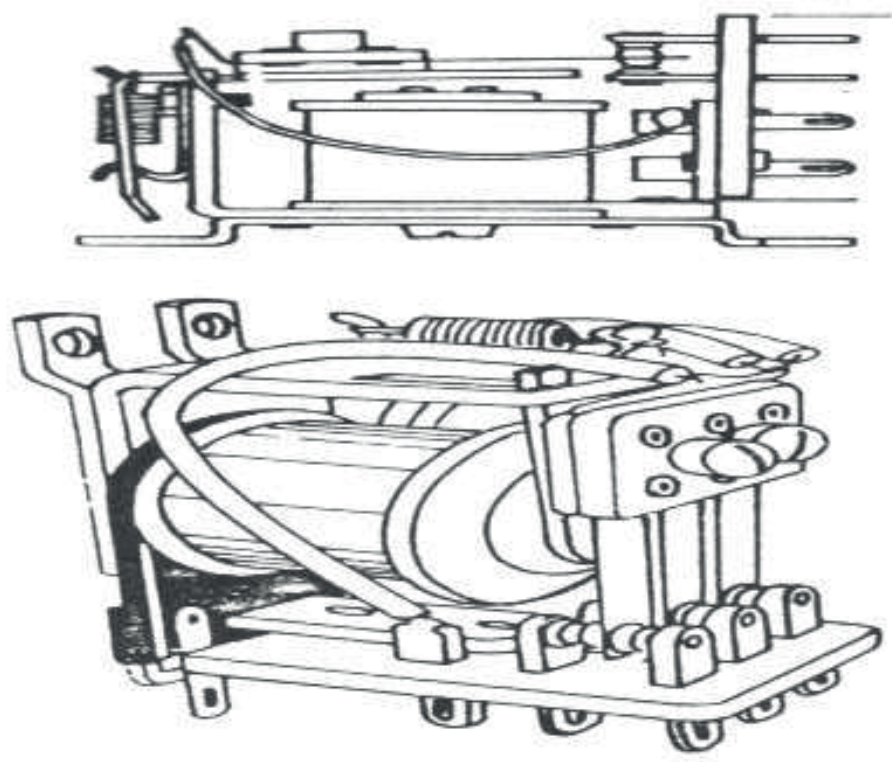
existen los relés temporizadores, que abren o cierran los contactos al cabo de un tiempo y que, a su vez, pueden conseguir esta temporización por medios neumáticos, térmicos, de relojería y electrónicos. Ejemplo de ellos son los que mostramos a continuación:
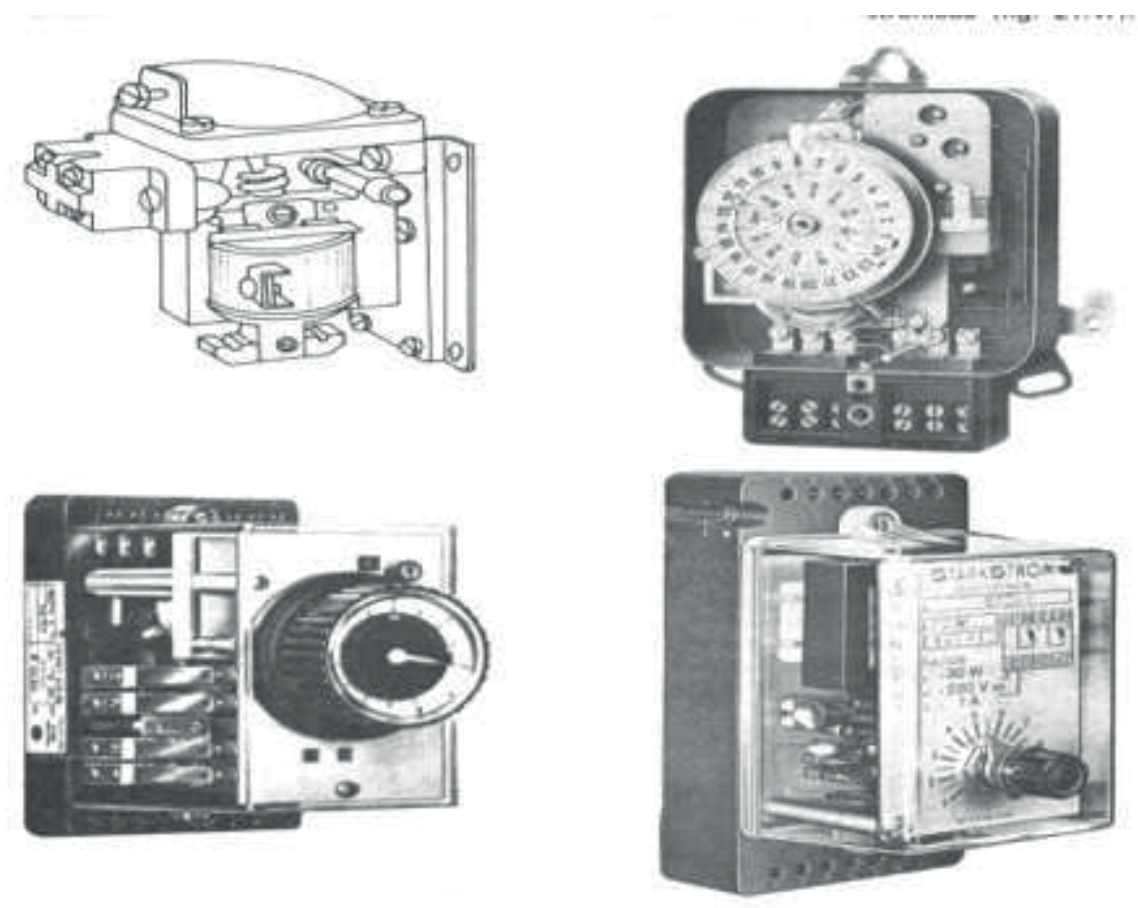
Las

citas dentro del texto del trabajo se harán utilizando el apellido del autor, la fecha de publicación y la página/s citada entre paréntesis si la cita hace referencia a páginas exactas, si no, irá sin número de las mismas ya que se entiende que se referencia todo el libro y/o artículo. Cada uno de los tres datos irá separado por una coma.

El Sistema Harvard-APA no requiere utilizar las citas a pie de página pero sí el Sistema Complutense de Citación (SCC).

Ejemplo:

Andrew Williams afirmaba que "al comprar los desórdenes de la personalidad se debe tener en cuenta la edad del paciente" (Williams, 1993, p.105).

\section{O Bien:}

Se ha considerado como muy frecuente que "al comprar los desórdenes de la personalidad se debe tener en cuenta la edad del paciente" (Williams, 1993, p. 105). 
Si hay varios libros en el mismo año del mismo autor, al lado del año se añadirá una letra correlativa alfabéticamente $(\mathrm{a}, \mathrm{b}, \mathrm{c}, \mathrm{d} \ldots)$ para luego añadirla igualmente en la bibliografía y así discernir entre un libro y otro del mismo año y su cita correspondiente.

Ejemplo:

Se plantea como inevitable que "la situación de los comunicadores en el siglo XXI pasa indefectiblemente por el manejo de las nuevas tecnologías" (Cabezuelo, 2009 b, p. 201)

Cuando la cita es indirecta (se menciona la idea del autor pero no se cita textualmente), no se coloca la página de la referencia. Se hace de la siguiente manera:

Es oportuno considerar la edad de los pacientes al estudiar los desórdenes de la personalidad (Williams, 1995)

Para citar a varios autores (hasta cinco) escriba los apellidos de todos los autores la primera vez que se les cite en el trabajo y en las citas posteriores utilice et al.

Cuando necesite hacer referencia a una fuente cuyo autor no ha podido identificar con precisión, cite las primeras dos o tres palabras del título, seguido por el año.

Por ejemplo:

... en una reciente publicación (Enciclopedia de la Psicología, 1991, p.62)...

... en el siguiente artículo ("Diferencias individuales". 1993, p.12)... 
Siga este ejemplo para las direcciones electrónicas donde no ha podido identificar ningún autor. Sin embargo, si el autor es "anónimo", cite la palabra Anónimo en su texto, por ejemplo:

(Anónimo, 1993, p.116)

\section{Notas a pie:}

Las notas a pie de página se numeran correlativamente y se referencian en cada página, evitándose juntarlas todas al final del texto. Obviamente el número siempre será arábigo e irá como superíndice (es decir en Book antiqua a 12 puntos, con 1,5 de interlineado y justificado sin sangría). El texto al pie de página irá:

El número en Book antiqua a 10 puntos.

El texto en Book antiqua. 8 Puntos. Espacio a 1,5. Justificado. Sin sangrado. No hay separación entre notas a pie de página ni el párrafo llevará Espaciado.

Ejemplo:

La memoria anual informativa supone una gran ventaja en el flujo comunicativo empresarial. Así, "entre los documentos escritos, la memoria anual es el informe amplio más conocido y de extraordinaria utilidad para los accionistas porque indica la existencia o no de reparto de beneficios". ${ }^{1}$ (Ejemplo) (Se inserta una NOTA A PIE, -menú insertar- y automáticamente aparecerá en el pie de la página el lugar para escribir el texto correspondiente, pero hay que escribirlo según normas: El texto en Book antiqua. 8 Puntos. Espacio a 1,5. Justificado. Sin sangrado. No hay separación entre notas a pie de página ni el párrafo llevará Espaciado)

2 (Ejemplo)

${ }^{3}$ (Ejemplo)

\footnotetext{
${ }^{1}$ La autora cita a LACLAU, Ernesto (1987). “Populismo y transformación del imaginario político en América Latina” en Boletín de Estudios Latinoamericanos y del Caribe, no 42, octubre 2005, pp. 25-38 y p. 109.

2 Es un tema recurrente en toda la obra de Gómez Sánchez, quien afirmó que: “Falta un elemento básico para comprender la realidad 2.0 a fecha de hoy, y es el papel que desempeñarán los medios tradicionales dentro de este nuevo mundo de la comunicación". (PONS i FERRÉ, 2007)

3 GARCÍA JIMÉNEZ, Jesús (1995): La Comunicación Interna. Díaz de Santos. Madrid. Pág. 143.
} 
Se evitará poner Op. Cit., pues cada vez que se cite una obra, aun ya citada, se consignará íntegra.

\title{
$\underline{\text { Citas literales dentro del texto: }}$
}

Book antiqua. Cuerpo 12. Interlineado 1,5. No sangrado. Márgenes de 4 centímetros izquierdo y derecho. Cursiva y entrecomillado.

Ejemplo:

En toda la obra de Cervantes hallamos referencias veladas a los enclaves geográficos, entendidos éstos como base de las andanzas de sus personajes. Así:

\begin{abstract}
"En un lugar de la Mancha, de cuyo nombre no quiero acordarme, no ha mucho tiempo que vivía un hidalgo de los de lanza en astillero, adarga antigua, rocín flaco y galgo corredor. Una olla de algo más vaca que carnero, salpicón las más noches, duelos y quebrantos los sábados, lantejas los viernes, algún palomino de añadidura los domingos, consumían las tres partes de su hacienda. El resto de ella concluían sayo de velarte, calzas de velludo para las fiestas, con sus pantuflos de lo mismo, y los días de entresemana se honraba con su vellorí de lo más fino."
\end{abstract}

Por lo que se puede concluir que su obra más inmortal no hace sino refrendar esta tendencia que en él es canónica.

Elisiones: Siempre entre corchetes.

Ejemplos:

"Entonces fue cuando la parte de las telecomunicaciones [...] acabó siendo la protagonista del proyecto presentado" 
"[...] es lo que se considera un éxito en la mercadotecnia del siglo XXI"

NOTA: LOS EPÍGRAFES Y SUBEPÍGRAFES TENDRÁN UNA LÍNEA DE CORTESÍA EN BLANCO POR ENCIMA Y POR DEBAJO.

Espacio en blanco

1. Epígrafe: Book antiqua. 14. Negrita. Minúsculas. Justificado. Espacio en blanco

1.1 Subepígrafe de $\mathbf{1}^{\mathrm{o}}$ nivel: Book antiqua. 12. Negrita. Minúsculas. Justificado.

Espacio en blanco

1.1.1 Subepígrafe de $2^{\circ}$ nivel: Book antiqua 12. Negrita. Cursiva. Minúscula. Justificado.

Espacio en blanco

1.1.1.1 Subepígrafe de $3^{\circ}$ nivel: Book
antiqua 12. Cursiva. Minúscula.
Justificado. (SI ES POSIBLE SE
EVITARÁ LLEGAR A ESTE
SUBNIVEL)

Espacio en blanco

2.

3.

4. Bibliografía

5. Webgrafía 


\section{Bibliografía (va numerada como epígrafe correlativamente con los} demás del texto)

Al final del texto se recogerá por orden alfabético del primer apellido del autor (o primer autor en obras colectivas). Si el autor presenta varias obras en el mismo año se incluirá en el año una letra (a, b, c, d...) para distinguir lo libros que han sido citados en el texto de esta misma manera.

Se escribirá siempre la reseña del autor completa (APELLIDOS, Nombre) aunque haya escrito varios libros por lo que alfabéticamente irían seguidos en la lista. Es decir, se evitará la moda de escribir para indicar que el autor del libro nombrado es el mismo autor que el del libro anterior en el listado.

(NOTA: Las referencias bibliográficas se presentan de la siguiente manera tanto al final del texto (en el apartado de Bibliografía) como en las notas a pie de texto)

Formas de citar distintos tipos de fuentes bibliográficas:

(NOTA: Si no se conoce el nombre de pila valdrá la inicial seguida de un punto. Si hay varios autores irán citados uno tras otro, separados por comas hasta el último que irá unido por el nexo "y". Para Muchos autores se citará el primero y se añadirá "y otros". Si el autor es anónimo, se escribirá ANÓNIMO, como si del apellido se tratara. Se citará el número de páginas sólo si corresponden exactamente a la cita, de tratarse de un artículo citado genéricamente dentro de un libro no hará falta)

- Libro: (No se citan las páginas consultadas al final de la referencia en la Bibliografía final, pero sí en la nota a pie o en el sistema parentético empleado dentro del texto)

SOMONTES DE DIEGO, Ángel, GARCÍA PÉREZ, Luis y BLANCO FUENTE, E. Benito (1979): Los elementos del estilo ( $3^{\mathrm{a}} \mathrm{ed}$.). Bruguera. Barcelona.

PÉREZ GARCÍA, Jorge y otros (2009): La indulgencia del ateo. Ed. 4 de Agosto. Logroño.

\section{- Capítulo de un libro:}


VYGOTSKY, León. (1991): “Génesis de las funciones mentales más altas" en PÉREZ PONS, Jorge y otros: Los límites del pensamiento (pp. 32-44). Planeta. Barcelona.

\section{- Artículos de revistas o periódicos:}

GÓMEZ LÓPEZ, Luis (2001): “Gestión para la supervivencia de Daewoo en España" en Revista Telos, nº 101 de Octubre de 2008. Pág. 22-23.

\section{- Fuentes electrónicas:}

CALDEVILLA DOMÍNGUEZ, David (2009): "Iberismo y prospectiva" en Revista Vivat Academia, $\mathrm{n}^{\mathrm{o}}$ 107. Julio-Agosto 2009. Disponible en: www.ucm.es/info/vivataca/numeros/n107/articulo.htm\#RP (Consultado el $23 / 10 / 2010)$

Webgrafía (va numerada como epígrafe correlativamente con los demás del texto) (Es la NO citada expresamente en el anterior epígrafe de Bibliografía como Fuente electrónica) (va numerada correlativamente con el texto)

Irá separada si se citan páginas de Internet genéricas, sin referencia al autor, pues si el autor es conocido se citará como si de una fuente electrónica se tratara -véanse líneas más arriba-.

www.imdb.com

www.rae.es

www.scribd.com/doc/34589521/On-Distributed-Communications

NÍHIL ÓBSTAT . IMPRIMÁTUR 